Check for updates

Cite this: RSC Adv., 2017, 7, 40973

\title{
Fluorescent carbon dots: rational synthesis, tunable optical properties and analytical applications
}

\begin{abstract}
Yifan Wang, ${ }^{a}$ Yanwu Zhu, ${ }^{a}$ Shaoming $\mathrm{Yu}^{* a}$ and Changlong Jiang (D) *b
Carbon dots (CDs) are a new type of fluorescent carbon nanoparticles (CNPs). In comparison with conventional semiconductor quantum dots and organic dyes, CDs not only have the advantages of nontoxicity and high biocompatibility, but also have excellent water solubility, an adjustable luminous range, high photostability, an absence of light flicker, easy functionality, rich sources of cheap raw materials, easy large-scale syntheses and other excellent characteristics. These excellent properties endow CDs with great potential in many fields, such as environmental monitoring, sensors, catalysis, energy, lightemitting devices, cell markers and biological imaging. With these excellent properties, as well as important applications, CDs have attracted widespread attention in recent years. This article reviews recent progress in CDs in terms of their rational synthesis, tunable optical properties, and analytical applications and put forward the developmental trend of CDs.
\end{abstract}

Received 10th July 2017

Accepted 9th August 2017

DOI: 10.1039/c7ra07573a

rsc.li/rsc-advances

However, QDs are expensive, difficult to synthesise, and highly toxic, which limits their applications in environmental monitoring, biosensors and biological imaging. ${ }^{2}$ Therefore, many efforts have focused on the facile synthesis and rational design of other fluorescent nanomaterials with lower toxicity for a wider range of applications.

Fluorescent CDs, which are a new class of carbon nanomaterials with sizes of less than $10 \mathrm{~nm}$, have attracted many researchers because of their superior resistance to photobleaching, low toxicity, high chemical stability and photostability, excellent biocompatibility, low cost, and abundant raw materials in nature..$^{3-5}$ Carbon is commonly a black material and was generally considered to have low solubility in water and weak fluorescence. On the other hand, CDs can be surfacepassivated by organic compounds or biomolecules to become strongly fluorescent in the visible and near infrared spectral

${ }^{a}$ Anhui Province Key Laboratory of Advanced Catalytic Materials and Reaction Engineering, School of Chemistry and Chemical Engineering, Hefei University of Technology, Hefei, Anhui, 230009, China. E-mail: shmyu@hfut.edu.cn

${ }^{b}$ Institute of Intelligent Machines, Chinese Academy of Sciences, Hefei, Anhui, 230031, China.E-mail: cljiang@iim.ac.cn

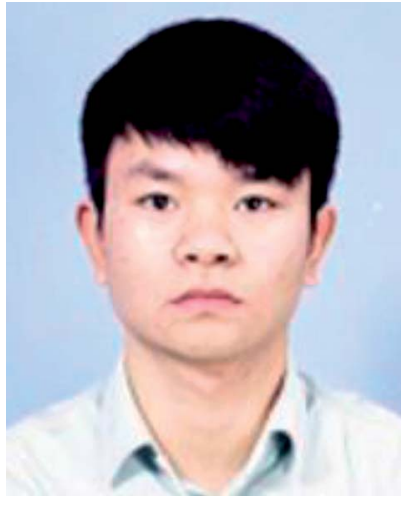

Yifan Wang received his $B S$ degree from Anhui University of Science \& Technology in China in 2015. He is currently a master's student with Professor Shaoming Yu at Hefei University of Technology. His research interests focus on the preparation of functional nanomaterials and their application in environmental analysis.

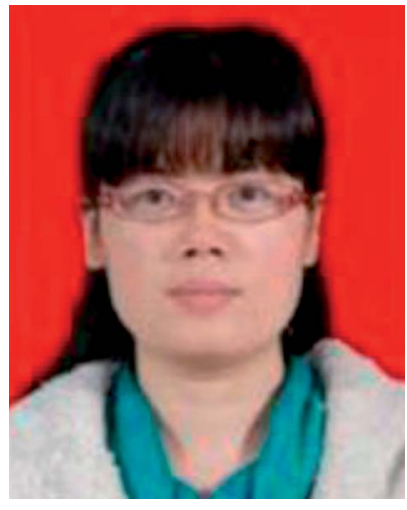

Yanwu Zhu is an associate professor at Hefei University of Technology. She received her $B S$ (1999) and MS (2002) degrees from Anhui Normal University and obtained her PhD degree (2009) from Anhui Institute of Optics and Fine Mechanics, Chinese Academy of Sciences. Her research interests focus on the synthesis of nanomaterials, photocatalytic degradation, and fluorescent sensors, etc. 
regions. CDs also exhibit very high two-photon absorption cross-sections, which enables fluorescence imaging via both one- and two-photon excitations on the same platform. ${ }^{6,7}$ Thus, CDs have been employed in many fields, such as environmental monitoring, sensors, catalysis, bioimaging, etc., owing to their tunability and good optical properties. Xu et al. ${ }^{8}$ discovered the first example of fluorescent CDs when they were purifying SWCNTs from arc-discharged soot. Subsequently, Sun et al. ${ }^{9}$ pioneered the synthesis of CDs by laser ablation of graphite powder using argon as a carrier gas in the presence of water vapor, successfully employed them in multi-photon imaging, and first named them CDs.

The rational design of fluorescent CDs with tunable optical properties is vital for a wide range of applications in many analytical fields. This review will summarize current advances in the rational design of fluorescent CDs, their employment in optical sensors and their potential applications in a wider range of fields. Rational synthetic strategies for the controllable preparation of fluorescent CDs with tunable optical properties will be first introduced. Next, recent progress in the tunable optical properties of fluorescent CDs will be discussed. Then, potential applications of fluorescent CDs in various fields, including biological sensing and imaging, environmental monitoring, explosives screening and food safety control will be reviewed. Finally, an outlook and conclusion will also be presented.

\section{Rational synthesis of fluorescent CDs}

As a new member of the family of carbon nanomaterials, CDs have attracted much attention and aroused great interest. In order to obtain CDs with more stable structures, enhanced properties, more versatile functions and a wider range of potential applications, several synthetic strategies have been reported, including laser ablation of graphite, electrochemical oxidation of graphite or multi-walled carbon nanotubes, microwave pyrolysis of solutions of saccharides (e.g., glucose) in the presence of poly(ethylene glycol), and hydrothermal treatment of glucose or orange juice. ${ }^{7,10,11}$ In general, methods for the synthesis of fluorescent CDs can be divided into two categories, namely, top-down and bottom-up routes. ${ }^{12}$ Some typical strategies, synthetic methods, precursors, etc., are listed in Table 1. Fluorescent CDs have been extensively studied for their interesting and unique properties and potential applications, which can enable new approaches and critical improvements in the field of sensors. ${ }^{\mathbf{1 3 - 1 6}}$

\subsection{Top-down approaches}

Top-down approaches mainly break down large-sized carbon precursors (e.g., graphite, carbon nanotubes, carbon black, activated carbon and graphene oxide, etc.) into small-sized CDs by physical or chemical methods, including arc discharge, ${ }^{8}$ laser ablation, ${ }^{6,9,17,18}$ electrochemical oxidation, ${ }^{19-25}$ and so on.

2.1.1 Arc discharge. Xu et al. ${ }^{8}$ obtained a new type of fluorescent carbon nanomaterial by the purification of single-walled carbon nanotubes synthesized by arc discharge, which was the first report of the discovery of fluorescent CDs. As was reported, arc ash was oxidized with nitric acid, and then a large quantity of carboxyl groups was generated on the surface, which resulted in an increase in the aqueous solubility of the material. The precipitate was further extracted with sodium hydroxide to form a stable black suspension after separation of the suspensions by gel electrophoresis.

Moreover, from single-walled carbon nanotubes and short carbon nanotubes, a mixture that emitted fluorescence was unexpectedly obtained in the product. The mixture was further separated to produce three kinds of fluorescent nanoparticles, which emitted blue, green, and yellow and orange fluorescence, respectively, under excitation at $366 \mathrm{~nm}$. Fourier transform infrared spectroscopy indicated that a large number of carboxyl groups were present on the surface of the CDs, but there was no characteristic peak of aromatic $\mathrm{C}-\mathrm{H}$ in-plane bending vibrations, which suggested that the fluorescence did not arise from aromatic compounds. Elemental analysis showed that the CDs mainly contained carbon and oxygen. The mass fraction of each

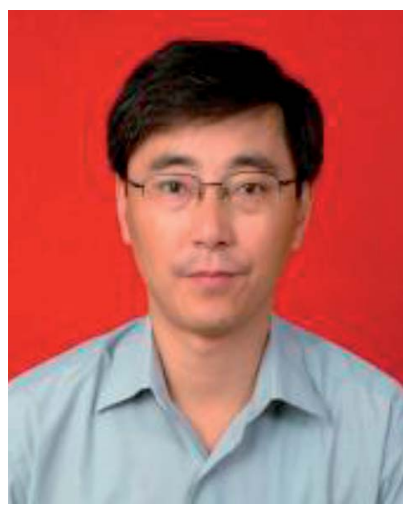

Shao-Ming $Y u$ received his $B E$ degree (1983) from the Department of Chemical Engineering, Hefei University of Technology and his $M E$ degree (1988) from the Department of Chemistry, East China University of Science and Technology. Then, he began his academic career at the School of Chemical Engineering, Hefei University of Technology. Since 1999, he has been a full professor. His research interests involve the preparation of functional nanomaterials and their application in catalysis, adsorption and chemical analysis.

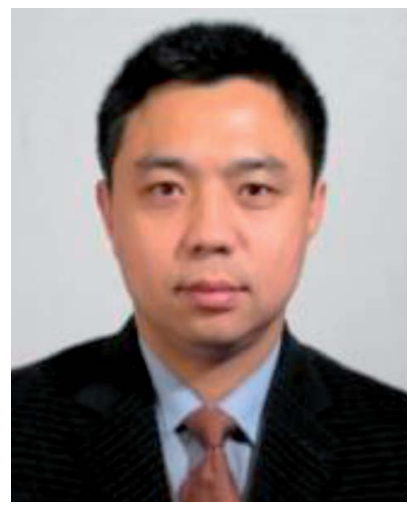

Changlong Jiang was born in Anhui, China. He received his PhD degree from the Department of Chemistry, University of Science and Technology of China in 2006. He moved to Japan afterwards and worked with Professor Kunihito Koumoto at Nagoya University, and then joined the group of Professor Xiaogang Liu at the National University of Singapore as a research scientist. He is a full professor at the Institute of Intelligent Machines, Chinese Academy of Sciences. His current research is focused on nanostructured materials, nanosensors, and nanoscale spectroscopic methods at the frontiers of environmental and nanoscale analysis. 


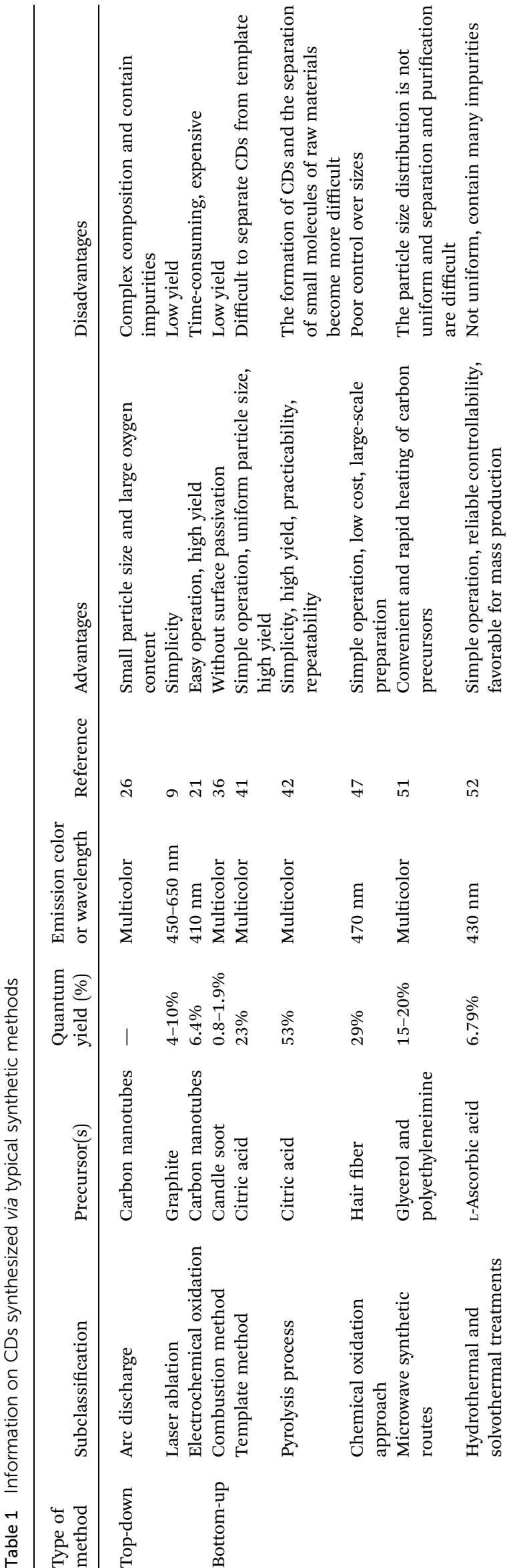

element was $\mathrm{C} 53.93 \%, \mathrm{H} 2.56 \%, \mathrm{~N} 1.20 \%$ and $\mathrm{O} 40.33 \%$, respectively, which indicated that the main components of the CDs were C, O, and a small amount of doped N. Subsequently, Bottini et $a l .{ }^{26}$ found that carbon nanotubes that emitted blue to yellow-green fluorescence could be obtained when single-walled carbon nanotubes prepared by arc oxidation were oxidized by nitric acid. The fluorescence peaks of the CNPs underwent a gradual red shift with an increase in molecular weight. CDs prepared by arc discharge have small particle sizes and large oxygen contents and can emit fluorescence without surface modification. However, CDs generated by arc discharge often have complex compositions and contain impurities, which are difficult to remove and extract.

2.1.2 Laser ablation. Laser ablation comprises the irradiation of a carbon target with a laser beam, which thereby detaches carbon nanoparticles from the carbon target to synthesize fluorescent CDs. Sun et al. ${ }^{9}$ pioneered the synthesis of CDs by laser ablation of graphite powder using argon as a carrier gas in the presence of water vapor and obtained nonfluorescent CNPs. However, upon passivation of the surface of acid-treated carbon particles by attaching simple organic species, bright luminescence emissions were observed (Fig. 1). By passivating the surface of the particles with aminopolyethylene (poly(ethylene glycol), PEG $_{1500 N}$ ), the obtained CNPs had a diameter of $5 \mathrm{~nm}$ and a luminous efficiency of 4-10\%. The emission of fluorescent CDs shifted from blue to red with the excitation wavelength, and subsequent studies found that most CDs have this feature. ${ }^{20,21,27-31}$ Moreover, Yang et $a .^{17}$ used a similar method with ${ }^{13} \mathrm{C}$ powder as the carbon source and, by optimizing the experimental parameters, obtained fluorescent CDs with a PL quantum yield of $20 \%$. Yang et al. ${ }^{18}$ simplified the synthetic strategy by combining laser ablation and passivation
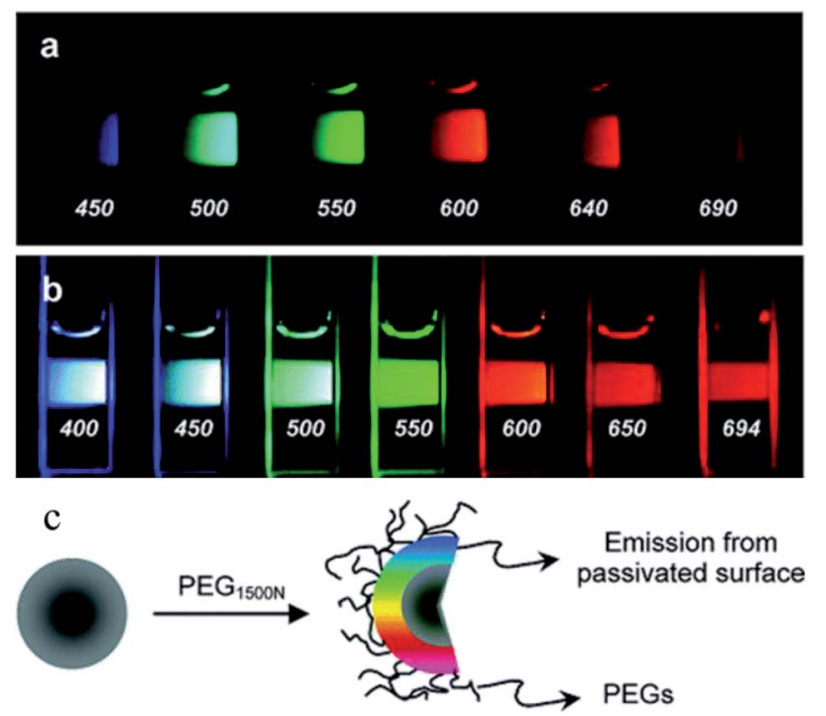

Fig. 1 Aqueous solution of CDs attached to $\mathrm{PEG}_{1500 \mathrm{~N}}$ (a) excited at $400 \mathrm{~nm}$ and photographed through band-pass filters of different wavelengths, as indicated, and (b) excited at the indicated wavelengths and photographed directly. (c) Schematic of passivation of CDs with $P E G_{1500 N}$. (Reprinted with permission from ref. 9. Copyright 2006, American Chemical Society.) 
in one step but changed the organic solvent (polyethylene glycol $\left(\mathrm{PEG}_{200 \mathrm{~N}}\right)$, hydrazine hydrate or diethanolamine), and CDs with different fluorescence emission wavelengths were prepared with different surface coatings. The synthesized CDs had an average size of $3 \mathrm{~nm}$ and a lattice spacing of $0.20-0.23 \mathrm{~nm}$, which is similar to that of diamond. Laser irradiation, oxidation, and passivation processes were usually required to synthesize CDs by laser ablation. The latter two steps were gradually simplified in subsequent fabrication procedures. However, CDs were produced by this method in low yields. The sizes of CNPs produced by laser irradiation are quite heterogeneous, and large CNPs are easily lost during centrifugation. The yields and utilisation efficiency of CDs obtained by this method are therefore low, which limits many potential applications.

2.1.3 Electrochemical oxidation. Electrochemical synthesis is a method of obtaining water-soluble CDs by electrolyzing carbonaceous materials such as graphite, carbon nanotubes, and so on. Zhou et $a .^{21}$ first used multi-walled carbon nanotubes as the working electrode, silver/perchlorate as the reference electrode and an acetonitrile solution containing $0.1 \mathrm{~mol} \mathrm{~L}^{-1}$ tetrabutylammonium perchlorate as the supporting electrolyte. The working electrode was treated by cyclic voltammetry to obtain CDs with a particle size of about $2.8 \mathrm{~nm}$ and a PL quantum yield of $6.4 \%$. Raman spectra showed that the CDs contained both $\mathrm{sp}^{2}$ carbon and irregular carbon, of which the lattice structure was similar to that of graphite. Studies have shown that the CDs produced in this experiment were generated during the voltage cycling process when tetrabutylammonium ions were inserted into defects in multi-walled carbon nanotubes. Yao et $a l .{ }^{25}$ placed a spectrally pure graphite ring anode and a titanium tube cathode in the center of an electrolyzer. The anode and cathode were separated by an insulating O-ring, and pure water was used as the electrolyte. At the same time, an electrolytic voltage and ultrasonic power were applied, and blue fluorescent CDs were rapidly obtained in pure water without complex purification. The size of the synthesized CDs was about 2-3 nm and their PL quantum yield was observed to be $8.9 \%$. Moreover, in recent years, some researchers have used ionic liquids (e.g., $[\mathrm{bmim}]\left[\mathrm{BF}_{4}\right]$ ) as an electrolyte to prepare CDs with emission peaks from the UV to the visible region (400$600 \mathrm{~nm}$ ) by adjusting the ratio of the ionic liquid to water. Unfortunately, their PL quantum yield was still low (2.8-5.2\%). In the course of many studies, it was found that alkaline conditions, i.e., the presence of a large number of $\mathrm{OH}^{-}$ions, are an important requirement for the synthesis of CDs by electrochemical oxidation. An advantage of the electrochemical preparation of CDs is that the synthesis of nanoparticles can be precisely controlled by adjusting the electrode potential and current density. Moreover, the preparation process enables easy operation and provides high yields. By this method, fluorescent CDs can be obtained without surface modification.

\subsection{Bottom-up approaches}

Unlike top-down approaches, which usually reduce the size of large particles, bottom-up methods for preparing CDs tend to proceed from small to large sizes. The main bottom-up approaches for synthesizing CDs from molecular precursors (e.g., citrate, ${ }^{32}$ carbohydrates $^{33,34}$ and polymer-silica nanocomposites $^{35}$ ) include combustion methods, ${ }^{36-38}$ template methods, ${ }^{35,39-41}$ pyrolytic processes, ${ }^{42-46}$ chemical oxidation approaches, ${ }^{3,47,48}$ microwave synthesis routes, ${ }^{49-51}$ and hydrothermal/solvothermal treatments. ${ }^{29,30,52-55}$ These methods are relatively simple, but the synthesised CDs generally have amorphous structures and their quantum efficiency is low on a large scale. However, the luminous efficiency of some CDs can be comparable to that of traditional semiconductor QDs.

2.2.1 Combustion methods. Combustion is a very common method of preparing CDs. The raw materials involved are simple and include candle ash, natural gas ash, paraffin putty, and so on. Liu et $a .^{36}$ reported for the first time the successful synthesis of CDs by burning candle ash. They collected ash from the incomplete combustion of a candle with aluminum foil and then placed it in $5 \mathrm{~mol} \mathrm{~L}^{-1}$ nitric acid solution to reflux. Finally, light-emitting CDs with higher dispersibility were obtained after centrifugation, transfer to a neutral medium, dialysis, etc. These CDs were separated by electrophoresis on a polyacrylamide gel. Then, CDs of which the emission wavelength underwent a gradual red shift on excitation at $315 \mathrm{~nm}$ with a particle diameter of about $1 \mathrm{~nm}$ were obtained according to the speed of electrophoresis. It is worth noting that the PL quantum yield of CDs prepared by this method was only 0.8$1.9 \%$. Subsequently, Ray et $a .^{37}$ adopted a simpler method to obtain CDs of a graphite structure with high dispersibility in water and ethanol but lower dispersibility in chloroform. The synthesis of CDs by combustion usually requires oxidative acid treatment, which has three important effects: (i) it fragments aggregates of CDs to obtain small nanoparticles; (ii) it ensures that CNPs can be dissolved in water; and (iii) it influences the fluorescence properties of carbon particles. CDs synthesized by this method can emit fluorescence without surface passivation, but their PL quantum yield is low.

2.2.2 Template methods. A problem that researchers often encounter when organically synthesising CDs at high temperatures is the agglomeration of CNPs. Fortunately, template methods can effectively prevent particle agglomeration and control the size of CDs. The synthesis process mainly involves two steps: (i) synthesising CDs by calcination in a suitable mesoporous template or silicon spheres and (ii) removing the support and generating nanosized CDs via etching. Bourlinos et $a .^{39}$ first synthesised CDs by a template method. They used NaY zeolite as the template to make 2,4-diaminophenol dihydrochloride react with the zeolite surface by ion exchange, and then heated it at $300{ }^{\circ} \mathrm{C}$. Finally, CDs were formed on the zeolite surface. The zeolite template was etched by hydrofluoric acid to obtain CDs with a PL quantum yield of $0.1 \%$ and a particle size of about 4-6 nm. Moreover, Liu et al. ${ }^{35}$ synthesized spherical polymer/F127/silica composites using soluble phenolic resin as the carbon source and functionalized the silica gel spheres with an amphoteric polymer. Amorphous water-soluble CDs with a particle diameter of 1.5-2.5 nm were obtained, and their PL quantum yield was $14.7 \%$. Zong et al. ${ }^{41}$ selected mesoporous silica spheres as the reaction template and citric acid as the carbon source. Silicon dioxide was immersed in citric acid 
solution, followed by calcination, etching with $\mathrm{NaOH}$ and dialysis to obtain CDs with particle diameters of 1.5-2.5 $\mathrm{nm}$ and a PL quantum yield of $23 \%$. The advantages of template methods are as follows: (i) the operation is simple and the equipment is easily available; (ii) the template is fixed during synthesis, which can control the size of the CDs and reduce their agglomeration; and (iii) the CDs have not only a uniform particle size but also high purity, so that later surface modification is convenient. The disadvantages are as follows: (i) it is difficult to separate the CDs from the template, and the removal of the template may affect the purity, particle size and luminescence properties of the CDs and (ii) the yield of the CDs is low. It is thus not suitable for the large-scale preparation of CDs.

2.2.3 Pyrolysis processes. Pyrolysis processes are methods of synthesizing CDs by carbonizing an organic substance at a high temperature. These methods generally require a high concentration of an alkali or strong acid to cleave carbon precursors into nanoscale colloidal particles. Wang et al. ${ }^{42}$ used a simple one-step approach to synthesize CDs. Typically, a mixture of $15 \mathrm{~mL}$ octadecene (non-coordinating solvent) and $1.5 \mathrm{~g}$ 1-hexadecylamine (surface passivation agent) was loaded into a three-neck flask and heated to $300{ }^{\circ} \mathrm{C}$ under an argon flow. Then, $1 \mathrm{~g}$ citric acid was added to the solution under vigorous stirring while keeping the temperature at $300{ }^{\circ} \mathrm{C}$ for $3 \mathrm{~h}$. The final products were purified by precipitation with acetone three times. The obtained CDs were highly soluble in common non-polar organic solvents. The highest PL quantum yield of oil-soluble CDs reached 53\% and remained constant for at least 2 months. In a similar process, by changing the reaction solvent and capping agent to glycerin and $\mathrm{PEG}_{1500 \mathrm{~N}}$, watersoluble CDs were synthesized at a temperature of $270{ }^{\circ} \mathrm{C}$ for $3 \mathrm{~h}$, and their PL quantum yield reached 17\% when excited at $360 \mathrm{~nm}$. Xie et $a l^{.33}$ and Wang et al. ${ }^{\mathbf{4 4}}$ used organosilanes as coupling agents and functionalizing agents and pyrolyzed a mixture of an organosilane and an organic acid to obtain silane-functionalized amorphous CDs in one step. Their size was about $0.9 \mathrm{~nm}$ and their PL quantum yield reached $47 \%$. Pan et al..$^{45}$ and Liu et al. ${ }^{46}$ used pyrolytic precursors to prepare CDs. These small-molecule precursors included ethylenediaminetetraacetic acid sodium salt, phenolic resin and hexaphenylbenzene. These methods have the advantages of simplicity, practicability and repeatability, and the CDs obtained have a high PL quantum yield. However, the formation of CDs and the separation of small molecules of the raw materials become more difficult.

2.2.4 Chemical oxidation approaches. Chemical oxidation approaches have been commonly employed to prepare CDs. CDs are easily obtained on a large scale upon the oxidation of carbon precursors by a strong oxidant. Peng et $a .^{3}$ demonstrated the facile synthesis of CDs on a large scale by the acid exfoliation and etching of pitch carbon fibers, which are rich in distributed graphitic domains in their original frameworks. The size of the as-prepared CDs varied with the reaction temperature, and their emission color and band gap could be controlled accordingly. They also showed the low cytotoxicity and excellent biocompatibility of these CDs, which can thus be used as an eco-friendly material in biolabeling and bioimaging. Sun et al. ${ }^{\mathbf{4 7}}$ developed a simple method for the synthesis of S-N-CDs on a large scale via the carbonization and etching of hair fibers by sulfuric acid. It was confirmed that the $\mathrm{S}$ content of the asprepared S-N-CDs increased with the reaction temperature, whereas the $\mathrm{N}$ content remained almost unchanged. This control of the atomic composition enabled the downconversion and upconversion PL properties of the S-N-CDs to be changed. The obtained S-N-CDs also exhibited high luminescence stability, nanosecond lifetimes, low toxicity, good biocompatibility, and high solubility in water and other polar organic solvents. Chemical oxidation approaches have the advantages of simple operation, the use of low-cost carbon raw materials, and the large-scale preparation of CDs with a narrow particle size distribution.

2.2.5 Microwave synthesis routes. Microwave synthesis routes are methods of synthesizing CDs by carbonizing small organic molecules in a short time via microwave heating. Zhu et al. $^{49}$ used a microwave method to obtain amorphous products with different sizes and different luminescence properties by changing the microwave processing time. Liu et al. ${ }^{\mathbf{5 0}}$ used glycerol as the carbon source and 4,7,10-trioxo-1,13tridecylenediamine as a surface passivation agent to prepare fluorescent CDs via microwave heating. The particle size was 2-7 $\mathrm{nm}$ and the PL quantum yield was $12 \%$. It was found that the incorporation of $\mathrm{N}$ atoms into CDs was very important for improving their fluorescence properties, but the yield of CDs was low. Subsequently, Liu et al. ${ }^{51}$ prepared amino-rich CDs using branched polyethyleneimine $\left(M_{\mathrm{w}}=25000\right.$, PEI $\left.25 \mathrm{kDa}\right)$ as a surface passivator, and the PL quantum yield was increased to 15-20\%. In comparison with other approaches, the carbon precursors are heated more conveniently and rapidly, which simplifies the synthesis process. CDs are therefore readily obtained within a few minutes with an improved yield. These methods are novel, green and efficient, and their employment in the synthesis of nanomaterials has aroused widespread attention among researchers. However, the particle size distribution is not uniform and separation and purification are difficult.

2.2.6 Hydrothermal/solvothermal treatments. Hydrothermal/ solvothermal treatments are low-cost, environmentally friendly, and non-toxic routes for producing novel carbon-based materials from various precursors. Typically, a solution of an organic precursor is sealed in a hydrothermal reactor and reacted at high temperature and high pressure. Zhang et al. ${ }^{52}$ reported for the first time that CDs were obtained by a one-step hydrothermal treatment. In the experiment, ascorbic acid was dissolved in deionized water, and then an ethanol solution was added. The reaction proceeded in an autoclave at $180{ }^{\circ} \mathrm{C}$ for $4 \mathrm{~h}$, followed by extraction with methylene chloride and dialysis through a cellulose dialysis membrane. Finally, CDs with a diameter of about $2 \mathrm{~nm}$ with a combination of graphitic and amorphous structures were obtained. The prepared CDs did not require treatment with a strong acid or surface modification, but their PL quantum yield was only 6.79\%. On this basis, Li et al. ${ }^{53}$ prepared nanofluids with $\mathrm{Ag} / \mathrm{SiO}_{2} /$ CDs, of which the fluorescence intensity increased with the thickness of the $\mathrm{SiO}_{2}$ layer. Moreover, Mohapatra et al. ${ }^{54}$ prepared highly photoluminescent CDs with a PL quantum yield of $26 \%$ in 


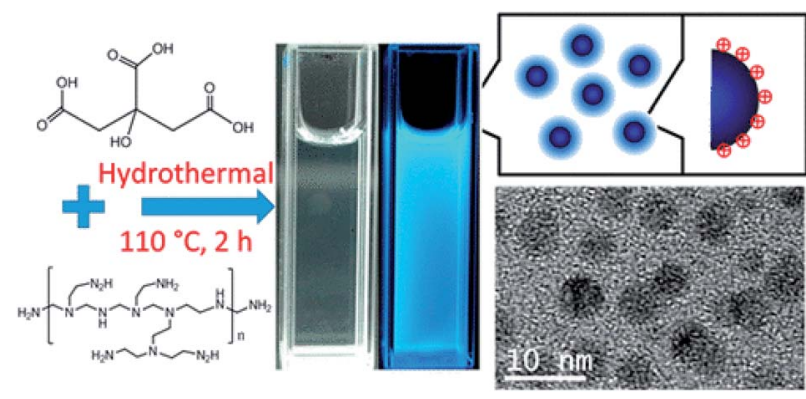

Fig. 2 Synthesis scheme and TEM image of CDs. (Reprinted with permission from ref. 56. Copyright 2017, American Chemical Society.)

one step by the hydrothermal treatment of orange juice followed by centrifugation. Yang et al. ${ }^{55}$ Sha $e t$ al. ${ }^{29}$ and Liu $e t ~ a l .{ }^{30}$ used chitosan, tobacco and grasses as carbon sources to prepare fluorescent CDs in an autoclave. As shown in Fig. 2 , Li et al. ${ }^{56}$ prepared blue luminescent CDs with a high PL quantum yield (48.3 $\pm 5.3 \%)$ by the one-pot hydrothermal reaction of citric acid with polyethyleneimine. Moreover, the as-prepared CDs displayed high dispersibility in water, resistance to photobleaching, salt tolerance, dispersibility in common solvents and complex media, and other useful properties, including upconverted and $\mathrm{pH}$-dependent PL. An advantage of these methods is that CDs with a high PL quantum yield can be obtained in one step in a reactor without further oxidation or passivation, which is favorable for mass production. Further advantages include simple operation, reliable controllability, and reaction in a closed reaction kettle, to avoid the volatilization of toxic substances. However, the size of the prepared CDs is not uniform, and the product often contains many impurities.

\subsection{Other methods}

In addition to the methods described above, methods for synthesizing CDs also include ultrasound and reverse micelle methods, etc. Li et al. ${ }^{19}$ prepared monodisperse water-soluble CDs by the ultrasonic activation of a mixed solution of carbon and hydrogen peroxide. The synthesized CDs emitted fluorescence that covered the visible and infrared regions and exhibited upconversion properties. Kwon et al. ${ }^{57}$ reported the facile synthesis of highly luminescent CDs employing reverse micelles as nanoreactors. The CDs were synthesized via hydrolytic polymerization, the subsequent carbonization of glucose and in situ passivation. The diameter of the prepared CDs was tuned from $1.8 \mathrm{~nm}$ to $4.1 \mathrm{~nm}$ by varying the water-surfactant ratio within the micelles.

\section{Tunable optical properties of CDs}

\subsection{Absorption}

CDs typically exhibit their main optical absorption in the UV region, mostly in the range of $250-320 \mathrm{~nm}$, with a tail extending to the visible region. The positions of the UV absorption peaks of CDs prepared by different methods are quite different. The absorption wavelength of modified CDs will increase correspondingly, or the absorption peak will be enhanced. Some of the absorption peaks can extend to the visible light region, or there can even be no significant absorption peak.

\subsection{Phosphorescence}

CDs show potential in lighting and displays. However, their fluorescence had not been observed until Deng et al. ${ }^{58}$ reported the observation of phosphorescence from CDs in a polyvinyl alcohol (PVA) matrix. This phosphorescence was attributed to $\mathrm{C}=\mathrm{O}$ bonds on the surface of $\mathrm{CDs}$ and had a very long lifetime $(\sim 380 \mathrm{~ms})$. They had obtained a pure organic RTP material based on a CD-PVA composite film. The phosphorescence emission peak was located at $500 \mathrm{~nm}$ with an average lifetime of $380 \mathrm{~ms}$ under excitation at $325 \mathrm{~nm}$. It was suggested that the phosphorescence originated from aromatic carbonyl groups in the CDs, and the PVA matrix effectively protected their triplet states from being quenched by intramolecular motions and oxygen. The pure organic, water-soluble and biocompatible room-temperature phosphorescent (RTP) material can be readily used in novel anti-counterfeiting applications, in particular for food and drugs. Its potential applications include chemical and biological sensing and time-resolved imaging.

\subsection{Photoluminescence (PL)}

PL is one of the most fascinating features of CDs. The mechanism of their tunable PL has not been fully investigated. Whether this occurs because of optical selection of nanoparticles of different sizes (quantum effect) and different emissive traps on the surface of CDs or another mechanism is currently unresolved. This is mainly due to the heterogeneity of the individual particles obtained by the same preparation process and the inconsistency of experimental observations, which occurs because the properties of CDs prepared by different routes are distinct and cannot be precisely defined. One unique property of the PL of CDs is the clear dependence on the value of $\lambda_{\text {ex }}$ of the emission wavelength and intensity. Sun et $a .^{59}$ used an organosilane as a coordinating solvent to synthesize highly luminescent (quantum yield $=47 \%$ ) amorphous CDs. When CDs with an average size of $1.54 \mathrm{~nm}$ were excited at $380 \mathrm{~nm}, 460 \mathrm{~nm}$ and $540 \mathrm{~nm}$, emissions with peaks at $460 \mathrm{~nm}, 540 \mathrm{~nm}$ and $620 \mathrm{~nm}$, respectively, were obtained. In the emission spectra of the CDs, the emission maximum was closely dependent on the excitation wavelength. The PL properties of CDs can be tuned via modification and the transfer of electrons or energy. ${ }^{60}$

\subsection{Chemiluminescence (CL)}

At present, work on CDs mainly focuses on their fluorescence properties and applications. Research into the use of CDs in CL analysis is still at the initial stage. Lin et al. ${ }^{61}$ first studied the CL properties of CDs when CQDs were in the presence of oxidants, such as $\mathrm{KMnO}_{4}$ and cerium(Iv). Electron paramagnetic resonance revealed that oxidants, such as $\mathrm{KMnO}_{4}$ and cerium(Iv), can inject holes into CDs. This process increases the population of holes in the CDs and accelerates electron-hole annihilation, which results in energy release in the form of CL emissions. 
Moreover, the CL intensity was dependent on the concentration of the CDs within a certain range. It was also found that an increase in temperature had a positive effect on the CL, because the electron distribution in the CDs was in thermal equilibrium, as shown in Fig. 3. The CL of CDs is thought to be due to the generation of positively charged and negatively charged CDs in the system. These then recombine to form CDs in the excited state, which emit CL upon returning to the ground state.

\subsection{Electrochemical luminescence (ECL)}

ECL is the result of the combination of electrochemistry and chemiluminescence ${ }^{62,63}$ and has many advantages with respect to fluorescence and chemiluminescence. Chi et al. ${ }^{64}$ reported CDs that exhibited ECL behavior. The results showed that oxidized CDs prepared via the oxidation by nitric acid of activated carbon could be oxidized or reduced at a certain potential $(-1.5 \mathrm{~V}$ to $1.8 \mathrm{~V})$. The corresponding electrochemical luminescence process took place via an annihilation reaction. The prepared CDs could also generate strong ECL with $\mathrm{S}_{2} \mathrm{O}_{8}{ }^{2-}$ ions as a co-reactant.

\subsection{Upconversion luminescence}

The most widely studied materials with upconversion luminescence properties are rare earth elements doped with inorganic crystals, such as $\mathrm{NaYF}_{4}: \mathrm{Yb}^{3+}, \mathrm{Er}^{3+}$ (ref. 65) and $\mathrm{NaGdF}_{4}: \mathrm{Yb} /$ $\mathrm{Er},{ }^{66}$ etc. Moreover, CDs were also found to have fascinating upconversion optical properties. The upconversion luminescence properties of CDs can be attributed to a multi-photon activation process, in which the simultaneous absorption of two or more photons leads to the emission of light at a shorter wavelength than the excitation wavelength (anti-Stokes-type emission). The upconversion luminescence properties of CDs open up new opportunities for cell imaging by two-photon luminescence microscopy, as well as the design of highly efficient catalysts for applications in bioscience and energy technology. ${ }^{67}$ Yin et al. ${ }^{68}$ employed fresh pepper as a precursor to synthesize high-quality CDs with down- and upconversion fluorescence by low-temperature carbonization. From the fluorescence emission spectra of the CDs (Fig. 4a), interesting

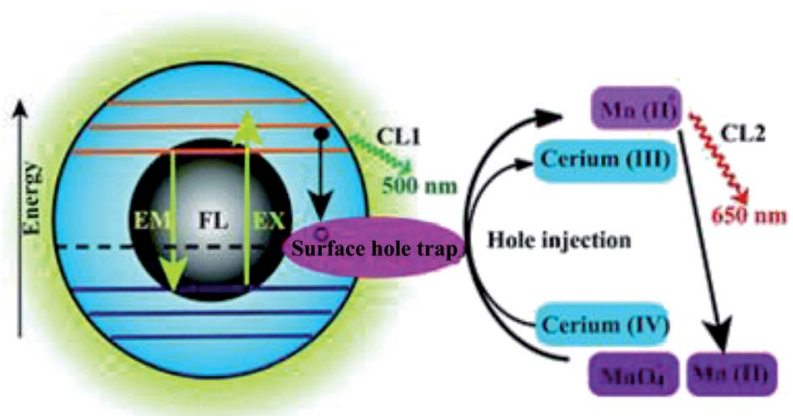

Fig. 3 Schematic illustration of the mechanisms of FL and $C L$ in the $\mathrm{CDs}-\mathrm{KMnO}_{4}$ and $\mathrm{CDs}-$ cerium(Iv) systems. CL1 and CL2 represent two $\mathrm{CL}$ pathways in the system. (Reprinted with permission from ref. 61. Copyright 2012, Royal Society of Chemistry.)

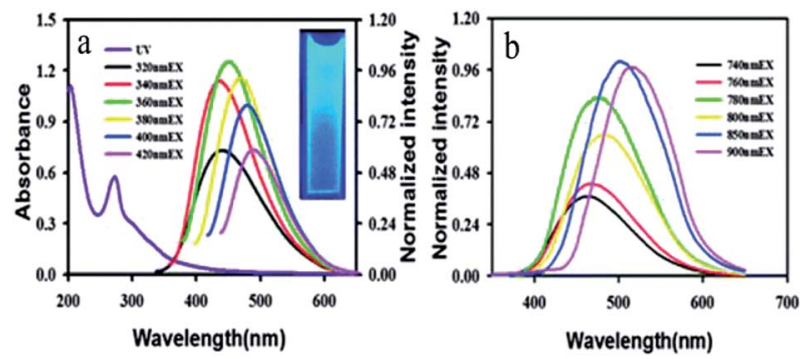

Fig. 4 (a) UV-vis absorption and emission spectra of CDs dispersed in water at excitation wavelengths progressively increasing from $320 \mathrm{~nm}$ to $420 \mathrm{~nm}$. Inset: a photograph of a dispersion of CDs under UV light (365 nm). (b) Upconversion FL properties of CDs. FL emission spectra of CDs dispersed in water at excitation wavelengths from $740 \mathrm{~nm}$ to $900 \mathrm{~nm}$. (Reprinted with permission from ref. 68. Copyright 2013, Royal Society of Chemistry.)

fluorescence properties such as down- and upconversion fluorescence were simultaneously observed in the experiments. The maximum emission band was shifted to longer wavelengths (from $430 \mathrm{~nm}$ to $500 \mathrm{~nm}$ ) with an increase in the excitation wavelength. Very strong upconversion fluorescence could also be observed with strong fluorescence emissions in the range of 400-600 $\mathrm{nm}$ at excitation wavelengths from $780 \mathrm{~nm}$ to $900 \mathrm{~nm}$ (Fig. 4b). This two-photon behaviour of CDs provides new evidence and suggests conditions for the widespread use of CDs.

\subsection{Tunable emission wavelengths}

The emission wavelength of most CDs is dependent on the excitation wavelength. With an increase in the excitation wavelength, the emission wavelength of CDs will be red-shifted and the fluorescence intensity will change accordingly. In general, it will first increase to a maximum and then decline. The emission wavelength of CDs is similar to the excitation wavelength, and the wavelength range is very large. Many prepared CDs can emit from the visible region to the near infrared region. The optical properties compensate for the shortcomings of traditional organic dyes in the near infrared region. Possible reasons for the tunability of the emission wavelengths are as follows: ${ }^{69}$ the particle sizes and particle size distributions of CDs are different, and the emission sites on the surface of each CD are different. At present, there are many uncertainties regarding the specific mechanism of the emission CDs, and knowledge is still at a speculative stage. Researchers therefore need to continue in-depth research and discussions in this area in the future.

\subsection{Other optical properties}

CDs also have many excellent fluorescence properties, such as broad and continuous excitation spectra, stable fluorescence and resistance to bleaching. ${ }^{35}$ Traditional organic dyes generally have a narrow excitation spectrum, and the excitation wavelengths of organic dyes differ. The excitation wavelength range of CDs is generally wide, and they can be excited from the ultraviolet region to the visible region. Therefore, synchronous 
detection procedures are more convenient. ${ }^{70}$ The fluorescence of traditional organic dyes will undergo fairly rapid decay during a long period of continuous exposure to excitation radiation, which indicates that these organic dyes have poor resistance to photobleaching. Such optical properties are detrimental for long-term biomarking and the detection of biomarkers, and the practical applications of the dyes will be substantially limited. However, the intensity and stability of fluorescence do not decrease significantly when CDs are irradiated by excitation radiation for a long time. More importantly, the intensity remains unchanged and photobleaching phenomena do not occur. ${ }^{22,71}$

\section{Analytical applications of fluorescent CDs}

\subsection{Biosensing and bioimaging}

4.1.1 Biosensing. As versatile fluorescent nanomaterials, CDs have excellent properties, such as high solubility in water, flexible surface modification, non-toxicity, excitationdependent multicolor emissions, excellent biocompatibility, high cell permeability, and high photostability. CDs have therefore been utilized as biosensor carriers for detecting glucose ${ }^{72,73}$ phosphate $^{74} \mathrm{pH}^{75}$ metal ions ${ }^{15,76-78}$ and deoxyribonucleic acid (DNA) in cells, proteins, enzymes and even pathogenic bacteria.

Shen et $a l .{ }^{73}$ presented a novel strategy for fabricating fluorescent boronic acid-modified CDs for non-enzymatic blood glucose sensing applications. The functionalized CDs were obtained by one-step hydrothermal carbonization using phenylboronic acid as the sole precursor (Fig. 5a). As shown in Fig. 5b, the addition of glucose led to the selective assembly of the CDs via covalent bonding between cis-diol groups of glucose and boronic acid groups on the surface of the CDs, which resulted in

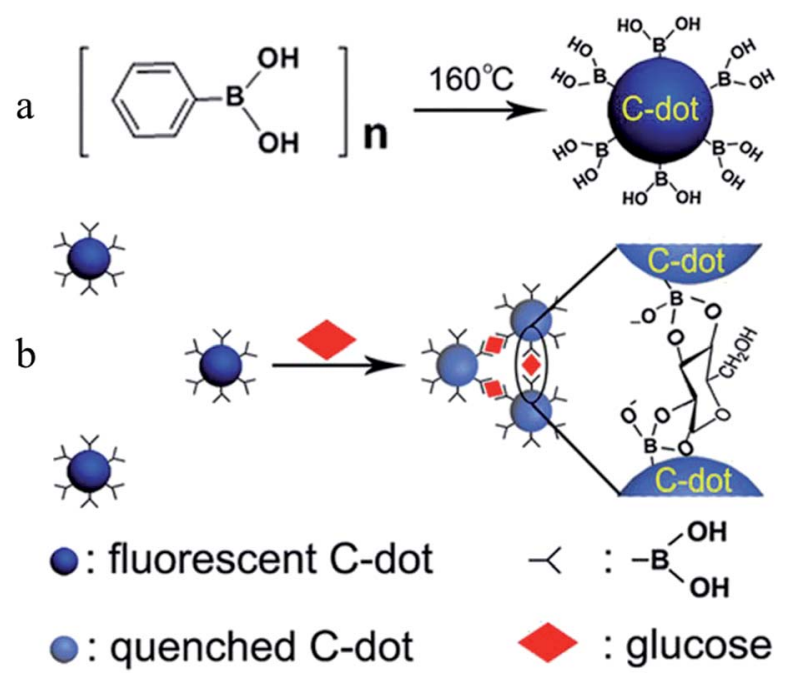

Fig. 5 Schematic showing (a) the formation of boronic acid-functionalised CDs and (b) the working principle for the sensing of glucose. (Reprinted with permission from ref. 73. Copyright 2014, American Chemical Society.) linear fluorescence quenching in the range of 9-900 $\mu \mathrm{M}$ with a detection limit of $1.5 \mu \mathrm{M}$. The proposed sensing system has been successfully used for the assay of glucose in human serum. $\mathrm{Yu}$ et $a .^{79}$ successfully prepared amino-modified fluorescent CDs, and a naphthalimide azide probe compound was attached to the surface of the CDs by covalent bonding. A sensor based on the principle of fluorescence resonance energy transfer was used to detect $\mathrm{H}_{2} \mathrm{~S}$ in water samples, serum and living cells. Du et $a l .{ }^{80}$ demonstrated a multifunctional fluorescent nanoprobe for detecting $\mathrm{H}_{2} \mathrm{O}_{2}$ in mitochondria. The nanoprobe was prepared by covalently linking a mitochondria-targeting ligand (triphenylphosphonium, TPP) and an $\mathrm{H}_{2} \mathrm{O}_{2}$ recognition element (PFl) to CDs. In this nanoprobe, the CDs serve as a carrier and a fluorescence resonance energy transfer donor. In the presence of $\mathrm{H}_{2} \mathrm{O}_{2}$, PFl moieties on CDs undergo structural and spectral conversion, which enables the nanoplatform to act as a FRETbased ratiometric probe for $\mathrm{H}_{2} \mathrm{O}_{2}$. The nanoprobe displays excellent water dispersibility, high sensitivity and selectivity, satisfactory cell permeability, and very low cytotoxicity. After uptake into a living cell, this nanoprobe can specifically target and stain the mitochondria, and it can detect exogenous $\mathrm{H}_{2} \mathrm{O}_{2}$ in L929 cells, as well as mitochondrial $\mathrm{H}_{2} \mathrm{O}_{2}$ endogenously produced in RAW 264.7 cells upon stimulation by PMA.

4.1.2 Bioimaging. Bioimaging includes in vitro bioimaging and in vivo bioimaging. As previously discussed, CDs have multiple advantages, including comparable optical properties and good chemical and photochemical stability. Most importantly, carbon is largely non-toxic and biocompatible. These traits make CDs very desirable as alternatives to semiconductor QDs and organic dyes for visualising biological systems both in vitro and in vivo.

Cao et $a .^{6}$ first reported the use of CDs in cell imaging, followed by a large number of studies of CDs in this area. They synthesized CDs by laser ablation using poly(propionylethyleneimine-co-ethyleneimine) (PPEI-EI, with an EI fraction of $\sim 20 \%$ ) as a surface passivation agent. The CDs were modified to increase their water solubility, which was followed by in vitro bioimaging studies. The CDs were found to be strongly emissive in the visible region upon excitation by either an argon ion laser $(458 \mathrm{~nm})$ or a femtosecond pulsed laser for two-photon excitation in the near infrared region $(800 \mathrm{~nm})$. As compared in Fig. 6, one- and two-photon luminescence images of the same scanned area match well, and the CDs were able to label both the cell membrane and the cytoplasm of MCF-7 cells without reaching the nucleus to a significant extent (Fig. 6d). Although endocytosis is likely, an understanding of the internalization mechanism still requires more investigation. Because of their higher water solubility and biocompatibility, functionalized CDs can be employed as nanoprobes in disease diagnosis and drug targeting applications. The transferrin receptor is a transmembrane glycoprotein and is expressed at low levels in normal somatic cells. Owing to their rapid growth, the demand for iron of tumor cells increases dramatically, and transferrin receptors exhibit high levels of expression in many tumor cells. On this principle, Li et al. ${ }^{\mathbf{1}}$ functionalized prepared CDs with the glycoprotein transferrin as a modifying agent. Owing to the specific binding of the ligand and the receptor, transferrin enhanced the targeting of CDs to tumor 

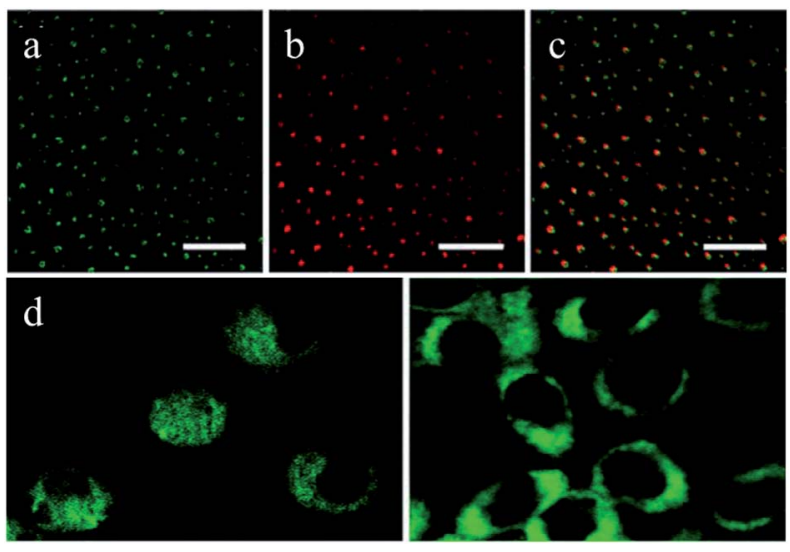

Fig. 6 Luminescence images (all scale bars $20 \mu \mathrm{m}$ ) of CDs upon excitation by (a) an argon ion laser at $458 \mathrm{~nm}$ and (b) a femtosecond pulsed laser at $800 \mathrm{~nm}$; (c) overlay image of (a) and (b); (d) representative two-photon luminescence images (excitation at $800 \mathrm{~nm}$ ) of MCF-7 human breast cancer cells with internalized CDs. (Reprinted with permission from ref. 6. Copyright 2007, American Chemical Society.)

cells. The results of electron microscopy revealed that CDs modified with transferrin combined well with a HeLa human cervical cell line and entered HeLa cells in large numbers. The fluorescence imaging effect of transferrin-functionalized CDs was obviously better than that of unmodified CDs.

In vitro imaging outside the organism can only provide limited information. For the complex disciplines of the life sciences, simple in vitro observations of cells are insufficient; many complex problems need to be resolved via in vivo research. The particle sizes, surface charge, low cytotoxicity and sufficient cellular uptake of nanomaterials are important parameters for in vivo imaging and targeted therapy. Yang et al. were the first to investigate the viability of CDs as contrast agents in live mice. ${ }^{\mathbf{8 2}}$ They obtained CDs and ZnS-doped CDs via chemical processing of raw nanomaterials by laser ablation. After modification with $\mathrm{PEG}_{1500 \mathrm{~N}}$, they were used for in vivo optical imaging of mice. CDs passivated by $\mathrm{PEG}_{1500 \mathrm{~N}}$ were injected subcutaneously into mice and bright fluorescence emissions were observed, which only decayed $24 \mathrm{~h}$ after the injection. If CDs were injected intravenously, emissions were only observed in the bladder region, which thereby suggested that excretion in urine is the main excretion route for intravenously introduced CDs. Because the particles displayed high biocompatibility and low toxicity, they might constitute an important contrast agent.

\subsection{Environmental monitoring}

In comparison with traditional semiconductor QDs and organic dyes, CDs are non-toxic carbon materials. In addition, they have the advantages of high biocompatibility, an adjustable luminous range, a large two-photon absorption cross-section, exceptional photostability, simple functionalization, affordability and convenient mass production. Therefore, they have great value for applications. By monitoring changes in their fluorescence intensity under external physical or chemical stimuli, CDs were used to detect substances such as $\mathrm{Hg}^{2+},{ }^{83-89}$ $\mathrm{Cu}^{2+},{ }^{90-94} \mathrm{Fe}^{3+},{ }^{95-98} \mathrm{Ag}^{+},{ }^{99,100} \mathrm{~Pb}^{2+},{ }^{101} \mathrm{Sn}^{2+},{ }^{102} \mathrm{Cr}(\mathrm{vI}),{ }^{103}$ and so on.

4.2.1 Cation detection. Divalent mercury ions, which are a type of heavy metal ion, are highly toxic and are recognized as one of the most dangerous and ubiquitous pollutants. They can easily penetrate human skin or enter the human body via the respiratory and digestive tracts and damage the human central nervous system and endocrine system, which poses a serious threat to human health. One of the first attempts to utilise CDs in chemical sensing was in the selective detection of $\mathrm{Hg}^{2+}$ ions. ${ }^{83-89}$ Zhou et al. ${ }^{83}$ for the first time reported a fluorescence sensor based on unmodified CDs for the label-free detection of $\mathrm{Hg}^{2+}$ ions and biothiols with high sensitivity and selectivity. They obtained CDs with an average particle size of $3.8 \mathrm{~nm}$ and a fluorescence quantum yield of $11.0 \%$ by pyrolysis of ethylenediaminetetraacetate. There was a linear relationship between fluorescence quenching and the concentration of mercury ions between $0 \mu \mathrm{M}$ and $3 \mu \mathrm{M}$, and the detection limit was $4.2 \mathrm{nM}$. Guo et al. ${ }^{84}$ developed a simple one-step hydrothermal method for the synthesis of highly fluorescent CNPs with a high quantum yield (68\%) and high photostability. This method required a shorter reaction time and a lower reaction temperature in comparison with previously reported methods. The as-prepared CNPs exhibited excellent emission properties and high stability, as well as excitation-independent emission behavior. Moreover, it was encouraging that the CNPs could be used as an effective fluorescent probe for the detection of mercury ions with high selectivity and sensitivity in an aqueous solution. $\mathrm{Lu}$ et $a l .{ }^{85}$ reported for the first time a simple, economic, and green preparation strategy for water-soluble fluorescent CNPs with a quantum yield of approximately $6.9 \%$ by a hydrothermal process using low-cost pomelo peel waste as a carbon source. They further investigated the use of such CNPs as probes for the fluorescence detection of $\mathrm{Hg}^{2+}$ ions, which was based on fluorescence quenching of CNPs induced by $\mathrm{Hg}^{2+}$ ions. This sensing system exhibited excellent sensitivity and selectivity toward $\mathrm{Hg}^{2+}$ ions, and a detection limit of as low as $0.23 \mathrm{nM}$ was achieved. The practical use of this system for the determination of $\mathrm{Hg}^{2+}$ ions in lake water samples was also demonstrated successfully. Our group ${ }^{\mathbf{8 6}}$ reported a new turn-on fluorescence nanosensor for the selective determination of $\mathrm{Hg}^{2+}$ ions based on CDs functionalized with bis(dithiocarbamato)copper(II) (CuDTC ${ }_{2}$-CDs). A $\quad$ CuDTC $_{2}$ complex was conjugated to prepared amine-coated CDs by the condensation of carbon disulfide with nitrogen atoms in surface amine groups, followed by the coordination of copper(II) to the resulting dithiocarbamate (DTC) groups and finally the additional coordination of ammonium $\mathrm{N}$-(dithiocarboxy)sarcosine (DTCS) to finally form the $\mathrm{CuDTC}_{2}-\mathrm{CDS}$ complex. As shown in Fig. 7, the $\mathrm{CuDTC}_{2}$ complex on the surface strongly quenched the bright blue fluorescence of the CDs by a combination of electron transfer and energy transfer mechanisms. $\mathrm{Hg}^{2+}$ ions could immediately switch on the fluorescence of the $\mathrm{CuDTC}_{2}$-CDs by promptly displacing $\mathrm{Cu}^{2+}$ ions in the $\mathrm{CuDTC}_{2}$ complex and thus shutting down the energy transfer pathway, by which a detection limit for $\mathrm{Hg}^{2+}$ ions of as low as $4 \mathrm{ppb}$ was reached. 
a
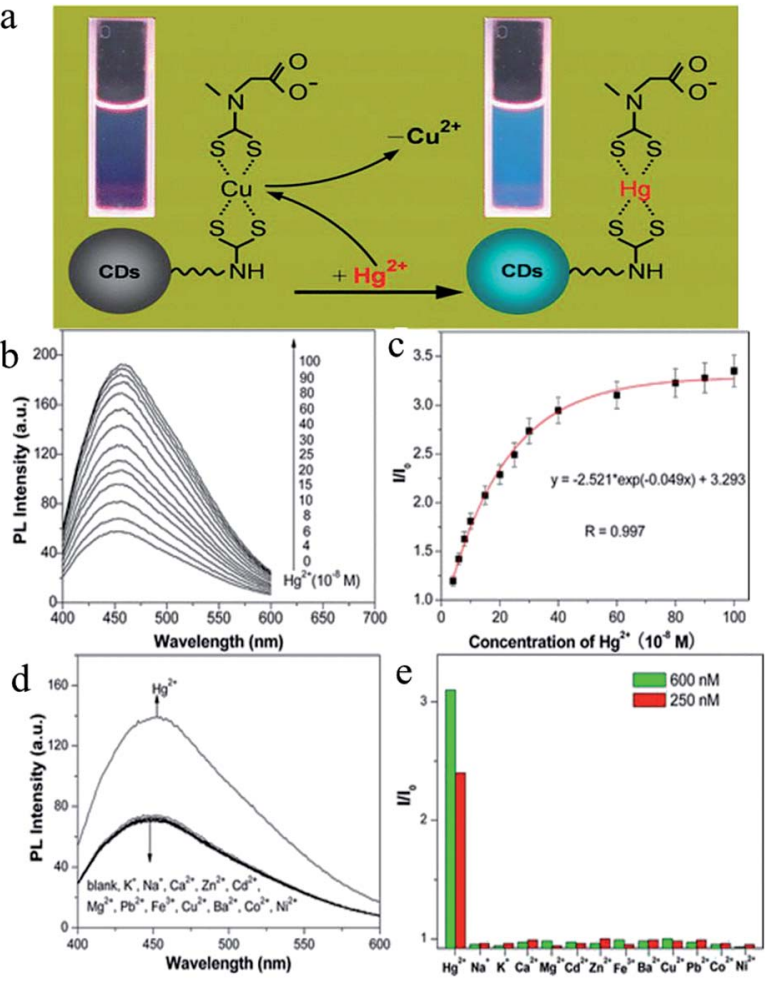

Fig. 7 (a) Schematic illustration of turn-on fluorescence nanosensor used to detect $\mathrm{Hg}^{2+}$ ions by the $\mathrm{Hg}^{2+}$-induced displacement of $\mathrm{Cu}^{2+}$ ions in a surface-bound $\mathrm{CuDTC}_{2}$ complex. (b) Fluorescence enhancement of a solution of the CuDTC 2 -CDs probe $\left(10 \mu \mathrm{g} \mathrm{mL}^{-1}\right)$ upon the addition of $\mathrm{Hg}^{2+}$ ions. (c) Plot of fluorescence enhancement as a function of the $\mathrm{Hg}^{2+}$ concentration. $I_{0}$ and $/$ represent the fluorescence intensity of the solution of the $\mathrm{CuDTC}_{2}-\mathrm{CDs}$ probe in the absence and presence of $\mathrm{Hg}^{2+}$ ions, respectively. (d) Fluorescence responses of the solution of the CuDTC ${ }_{2}-C D$ s probe $\left(10 \mu \mathrm{g} \mathrm{mL}^{-1}\right)$ in the presence of various metal ions. The concentrations of all metal ions were $150 \mathrm{nM}$. (e) Fluorescence enhancement $\left(/ / /_{0}\right)$ of the CuDTC $_{2}-$ CDs probe after the addition of metal ions at concentrations of $250 \mathrm{nM}$ and $600 \mathrm{nM}$, respectively. $I_{0}$ and / represent the fluorescence intensity of the solution of the $\mathrm{CuDTC}_{2}-\mathrm{CDs}$ probe in the absence and presence of metal ions, respectively. (Reprinted with permission from ref. 86. Copyright 2013, American Chemical Society.)

Copper, as a heavy metal ion and an essential trace element for many living organisms, ${ }^{\mathbf{1 0 4 , 1 0 5}}$ plays an important role in some physiological and pathological processes, such as bone formation and cellular respiration, as well as serving as a significant catalytic cofactor for the synthesis of hemoglobin, elastin and collagen. ${ }^{106}$ A deficiency of copper can lead to many diseases such as anemia, pancytopenia and bone abnormalities. ${ }^{107}$ Nevertheless, excessive $\mathrm{Cu}^{2+}$ concentrations may not only become toxic to living organisms and induce damage to the liver, kidneys and central nervous system (such as Wilson's disease and Alzheimer's disease) but can also lead to severe contamination of the environment by copper as a result of the widespread use of copper in agriculture and industry. ${ }^{102,108} \mathrm{Liu}$ et $a l .{ }^{30}$ developed for the first time a simple, low-cost, and green preparation strategy for water-soluble nitrogen-doped carbonrich photoluminescent polymer nanodots (PPNDs) by hydrothermal treatment of grass. It was suggested that an increase in the reaction temperature led to a decline in the size and an increase in the quantum yield of PPNDs. Most importantly, they further demonstrated a proof of concept that such PPNDs can serve as a very effective fluorescence sensing platform for the label-free sensitive and selective detection of $\mathrm{Cu}^{2+}$ ions with a detection limit of as low as $1 \mathrm{nM}$. The application of this method to detect $\mathrm{Cu}^{2+}$ ions in real water samples was also demonstrated successfully. Dong et al..$^{91}$ designed a novel sensing system for the detection of $\mathrm{Cu}^{2+}$ ions based on the quenching of the fluorescence (FL) signal of CDs functionalized with branched poly(ethyleneimine) (BPEI). $\mathrm{Cu}^{2+}$ ions can be captured by amino groups on BPEI-CDs to form an adsorbed complex on the surface of CDs, which results in strong quenching of the FL of the CDs via an inner filter effect. They demonstrated that this facile methodology can enable the rapid, reliable, and selective detection of $\mathrm{Cu}^{2+}$ ions with a detection limit of as low as $6 \mathrm{nM}$ and a dynamic range from $10 \mathrm{nM}$ to $1100 \mathrm{nM}$. Lin et al. ${ }^{92}$ synthesized novel highly fluorescent metal-organic frameworks (MOFs) by encapsulating CDs capped by branched poly(ethyleneimine) (BPEI-CDs) with a high FL quantum yield into zeolitic imidazolate framework materials (ZIF-8). The as-synthesized fluorescent functionalized MOFs not only maintained excellent FL activity and sensing selectivity derived from BPEI-CDs but also strongly and selectively accumulated target analytes owing to the adsorption property of MOFs. The selective accumulation effect of MOFs can greatly amplify the sensing signal and specificity of nanosized FL probes. The obtained BPEI-CDs/ZIF-8 composites were used to develop an ultrasensitive and highly selective sensor for $\mathrm{Cu}^{2+}$ ions with a wide response range $(2-1000 \mathrm{nM})$ and a very low detection limit ( $80 \mathrm{pM})$ and were successfully employed in the detection of $\mathrm{Cu}^{2+}$ ions in environmental water samples.

Other applications of CDs in cation sensing include the detection of $\mathrm{Fe}^{3+},{ }^{95-98} \mathrm{Ag}^{+},{ }^{99,100} \mathrm{~Pb}^{2+},{ }^{101} \mathrm{Sn}^{2+},{ }^{102}$ and $\mathrm{Cr}(\mathrm{vI})$ ions, ${ }^{103}$ and so on. Qu et al..$^{95}$ proposed a facile, economic and green one-step hydrothermal synthesis route to photoluminescent CNPs using dopamine as a carbon source. The as-prepared CNPs had an average size of about $3.8 \mathrm{~nm}$. They further demonstrated that such wholly new CNPs can serve as a very effective fluorescence sensing platform for the label-free sensitive and selective detection of $\mathrm{Fe}^{3+}$ ions and dopamine with detection limits of as low as $0.32 \mu \mathrm{M}$ and $68 \mathrm{nM}$, respectively. This new "mix-and-detect" strategy is simple and green and exhibits high sensitivity and selectivity. The method was also successfully employed for the determination of $\mathrm{Fe}^{3+}$ ions in real water samples and dopamine in human urine and serum samples. Li et al..$^{99}$ demonstrated the first use of CNPs obtained from carbon soot produced by lighting a candle as a cheap, effective fluorescence sensing platform for the detection of $\mathrm{Ag}^{+}$ ions with a detection limit of as low as $500 \mathrm{pM}$ and high selectivity. Wee et al. ${ }^{101}$ reported a simple and novel method for the synthesis of CDs via direct acid hydrolysis of bovine serum albumin in a one-pot approach. The fluorescence of the CDs was significantly quenched, in particular by $\mathrm{Pb}^{2+}$ ions, in a selective manner. The sensing probe had a dynamic linear range extending to $6.0 \mathrm{mM}$ with a Stern-Volmer constant of $605.99 \mathrm{M}^{-1}$ and a limit of detection of $5.05 \mu \mathrm{M}$. 
4.2.2 Anion detection. Lin et al. ${ }^{109}$ first employed CDs for the detection of nitrite ions. In their work, the CL properties of CDs in the presence of peroxynitrous acid were studied. Peroxynitrous acid is formed by the online mixing of nitrite ions and acidified hydrogen peroxide. The CL intensity increased linearly with the $\mathrm{NO}_{2}{ }^{-}$concentration in the range from $1.0 \times 10^{-7} \mathrm{M}$ to $1.0 \times 10^{-5} \mathrm{M}$, and the detection limit was $5.3 \times 10^{-8} \mathrm{M}$.

Zhao et al. ${ }^{74}$ used CDs functionalized with carboxyl groups to detect $\mathrm{PO}_{4}{ }^{3-}$ ions. The working principle is that the coordination of $\mathrm{Eu}^{3+}$ ions with carboxyl groups on the surface of the CDs leads to fluorescence quenching. The ability of $\mathrm{PO}_{4}{ }^{3-}$ ions to form a complex with $\mathrm{Eu}^{3+}$ ions is stronger than that of carbon, and the CDs are separated from the $\mathrm{Eu}^{3+}$ ions to restore their fluorescence.

Liu et al. ${ }^{110}$ designed a novel fluorescent probe (Zr(CDs$\mathrm{COO})_{2}$ EDTA) for the detection of $\mathrm{F}^{-}$content based on competitive ligand reactions that occurred between carboxylate groups $(-\mathrm{COOH})$ on the surface of the luminescent $\mathrm{CDs}$ and $\mathrm{F}^{-}$ions coordinated to $\mathrm{Zr}\left(\mathrm{H}_{2} \mathrm{O}\right)_{2}$ EDTA. The strong and stable fluorescence signal that was generated was quenched upon the addition of $\mathrm{F}^{-}$ions as a result of the formation of the nonfluorescent complex $\operatorname{Zr}(\mathrm{F})_{2}$ EDTA, because the affinity of $\mathrm{F}^{-}$ ions for $\mathrm{Zr}$ (Iv) ions was stronger than that of $\mathrm{COOH}$ groups in the CDs. The change in fluorescence $(\Delta F)$ in this process displayed a linear correlation with the $\mathrm{F}^{-}$content in the range from $0.10 \mathrm{mM}$ to $10 \mathrm{mM}$.

Hou et al. ${ }^{111}$ first applied the electrochemical luminescence properties of CDs in the detection of $\mathrm{S}^{2-}$ ions. They reported a fluorescence sensor based on CDs, which displayed excellent water solubility, low cytotoxicity and a short response time. The sensor was based on a ligand/ $\mathrm{Cu}^{2+}$ approach so as to achieve rapid sensing of sulfide anions. The CDs serve as the fluorophore as well as an anchoring site for ligands that bound to copper ions. In this CDs-based system, as copper ions bind to ligands that are present on the surface of the CDs, the paramagnetic copper ions efficiently quench the fluorescence of the CDs, which enables the system to act as a turn-off sensor for copper ions. More importantly, the subsequent addition of sulfide anions, which can extract $\mathrm{Cu}_{2} \mathrm{C}$ from the system to form very stable $\mathrm{CuS}$, results in fluorescence enhancement and enables the system to act as a turn-on sensor for sulfide anions. This rapidly responding and selective sensor can operate in an entirely aqueous solution or in a physiological medium with a low detection limit of $0.78 \mu \mathrm{M}$.

Other applications of CDs in anion sensing include the detection of $\mathrm{I}^{-112} \mathrm{C}_{2} \mathrm{O}_{4}{ }^{2-},{ }^{113} \mathrm{CN}^{-}$(ref. 114) and $\mathrm{O}_{2}{ }^{--}$ions, ${ }^{115}$ and so on.

Barman et al. ${ }^{\mathbf{1 1 2}}$ synthesized graphitic carbon nitride QDs (g-CNQDs) with strong blue fluorescence by a simple microwave-mediated method from formamide $\left(\mathrm{HCONH}_{2}\right)$. These QDs are highly sensitive and selective fluorescent probes for $\mathrm{Hg}^{2+}$ ions in aqueous media owing to the "superquenching" of fluorescence. The addition of $\mathrm{I}^{-}$ions abstracts bound $\mathrm{Hg}^{2+}$ ions to form $\mathrm{HgI}_{2}$ and restores the fluorescence characteristics of g-CNQDs. Thus, g-CNQDs can play a dual role in the selective and sensitive detection of $\mathrm{Hg}^{2+}$ ions, as well as $\mathrm{I}^{-}$ions, in aqueous media via an $\mathrm{ON}-\mathrm{OFF}-\mathrm{ON}$ fluorescence response.
Gao et al. ${ }^{115}$ developed a ratiometric fluorescence biosensor for $\mathrm{O}_{2}{ }^{--}$ions by employing CDs as a reference fluorophore and hydroethidine (HE) as an organic molecule that is specific for $\mathrm{O}_{2}{ }^{-}$ions, which plays the role of both a specific recognition element and a response signal. As shown in Fig. 8, CDs were first conjugated to the organic dye $\mathrm{HE}$, which is specific for $\mathrm{O}_{2}{ }^{-}$ ions, to form an inorganic-organic ratiometric fluorescence sensor for the detection of $\mathrm{O}_{2}{ }^{--}$ions with high selectivity and accuracy. The inorganic-organic fluorescence sensor exhibited high sensitivity, a broad dynamic linear range of $\sim 5 \times 10^{-7} \mathrm{M}$ to $1.4 \times 10^{-4} \mathrm{M}$, and a low detection limit of as low as $100 \mathrm{nM}$.

\subsection{Food quality control}

"Hunger breeds discontentment, food safety goes first". Since ancient times, food has been the basis of human survival and development, whereas food safety must be guaranteed for the promotion of human health. In recent years, there have been many food safety issues, so that increasing attention has been paid to food safety. In order to protect human health, more rigorous and accurate methods for detecting harmful, toxic and banned substances in food need to be developed.

Tartrazine, also known as lemon yellow, is a water-soluble synthetic pigment widely used as a coloring in ice cream, jelly, yogurt, beverages, canned foods, candy coatings and so on. However, some studies have revealed that tartrazine may cause adverse health effects such as changes in hepatic and renal parameters and reproductive toxicity, as well as neurobehavioral toxicity when consumed in excess. ${ }^{116,117}$ Therefore, the food industry must strictly control and regulate the content of tartrazine in foods, which necessitates an interest in the development of measurement techniques for determining tartrazine in foods that are efficient in terms of rapidity, simplicity, and sensitivity. $\mathrm{Xu}$ et al. ${ }^{118}$ found that tartrazine could result in strong quenching of the fluorescence of CDs that were synthesized from aloe via a hydrothermal process (Fig. 9a). The linear range was $0.25-32.50 \mu \mathrm{M}$, and the detection limit was $73 \mathrm{nM}$ (Fig. 9b). Moreover, as shown in Fig. 9c, various different substances were added to the test solution at an initial amount of 100 times that of tartrazine, and the ratio was gradually reduced when interference was present. It is worth noting that this method, when used to test steamed bread, honey, and rock

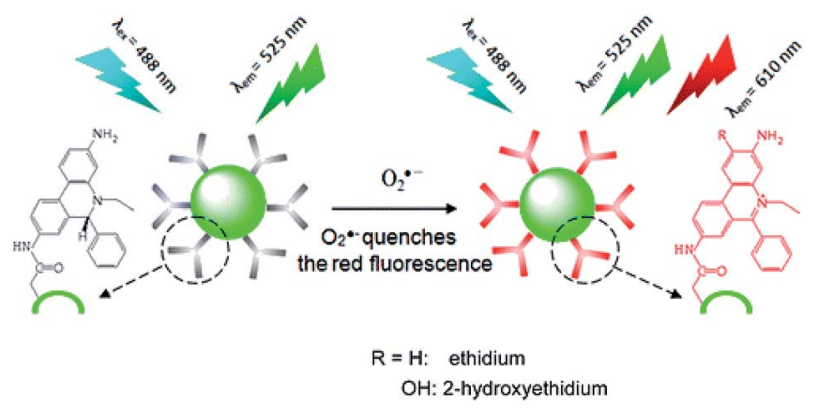

Fig. 8 Working principle of $\mathrm{CD}-\mathrm{HE}$ ratiometric fluorescence biosensor for $\mathrm{O}_{2}{ }^{--}$ions. (Reprinted with permission from ref. 115. Copyright 2014, American Chemical Society.) 
a
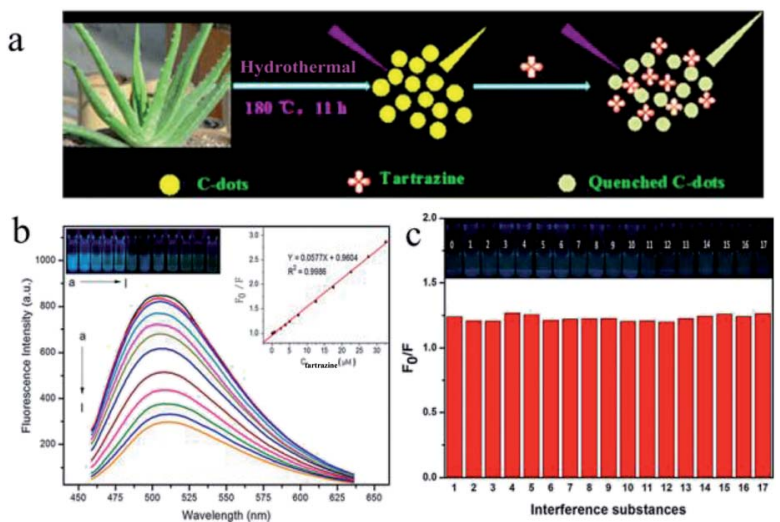

Fig. 9 (a) Scheme of the synthetic strategy of CDs and the working principle of tartrazine sensing. (b) Fluorescence emission spectra of CDs in the presence of different concentrations of tartrazine in $30 \mathrm{mM}$ PB (pH 6.0). From (a) to (l) $0.00,0.25,0.75,2.50,3.75,5.00,7.50,12.50$, $17.50,22.50,27.50$, and $32.50 \mu \mathrm{M}$, respectively; CDs, $450 \mu \mathrm{L}$. (Insets) Photographic images of the corresponding solutions under UV light and the curve for the relationship between $F_{0} / F$ and the concentration of tartrazine. (c) Effects of potentially interfering substances: (0) no interference; (1) glucose, $500 \mu \mathrm{M}$; (2) lactose, $500 \mu \mathrm{M}$; (3) starch, 500 $\mu \mathrm{M}$; (4) citric acid, $500 \mu \mathrm{M}$; (5) tartaric acid, $500 \mu \mathrm{M}$; (6) ascorbic acid,

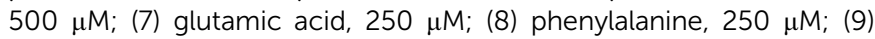
$\mathrm{NO}_{2}{ }^{-}, 500 \mu \mathrm{M}$; (10) $\mathrm{HCO}_{3}{ }^{-}, 500 \mu \mathrm{M}$; (11) $\mathrm{Ca}^{2+}, 500 \mu \mathrm{M}$; (12) $\mathrm{Zn}^{2+}, 500$ $\mu \mathrm{M}$; (13) $\mathrm{K}^{+}, 500 \mu \mathrm{M}$; (14) $\mathrm{Fe}^{3+}, 25 \mu \mathrm{M}$; (15) sunset yellow, $5.0 \mu \mathrm{M}$; (16) erioglaucine disodium salt, $25 \mu \mathrm{M}$; (17) amaranth, $5.0 \mu \mathrm{M}$. Conditions: CDs, $450 \mu \mathrm{L} ; \mathrm{PB}, 30 \mathrm{mM}, \mathrm{pH}$ 6.0, tartrazine, $5.0 \mu \mathrm{M}$. (Reprinted with permission from ref. 118. Copyright 2015, American Chemical Society.)

sugar, gave higher recoveries ( $24 \mathrm{~h} 88.6-103.4 \%$, $48 \mathrm{~h} 87.3-$ $106.6 \%$ ), which indicates that the method could be widely employed for the detection of tartrazine in foods.

Cysteine (Cys) is the only thiol-containing amino acid among the amino acids that constitute proteins in the body. It is unstable and easily oxidized and can be converted into cystine. It can be used for detoxification, the prevention and treatment of radiation injury, and the inhibition of cancer cells and bacterial growth. Therefore, Cys has important physiological functions and is widely used in the medical, food and other industries. The early diagnosis of certain diseases can be achieved by monitoring the concentration of Cys in the organism. In addition, it can be used in food products (such as health products, etc.) and human serum samples for the determination of Cys. Wu et al. ${ }^{98}$ synthesized CDs co-doped with nitrogen and sulfur via a facile hydrothermal method using citric acid and cysteine as precursors. The N,S-CDs acted as a highly sensitive and selective "turn-off-on" probe for the determination of $\mathrm{Fe}^{3+}$ ions or Cys. Upon the addition of Cys to the N,S-CDs/Fe $\mathrm{Fe}^{3+}$ system, the quenched FL intensity was recovered. The limits of detection were $14 \mathrm{nM}$ for $\mathrm{Fe}^{3+}$ and $0.54 \mu \mathrm{M}$ for Cys.

Glucose is the most widely distributed and most important monosaccharide in nature, and is a type of polyhydroxyaldehyde. Glucose has an important position in biology as the energy source of living cells and metabolic intermediates; that is, it provides the main energy supply for biological substances. Plants can produce glucose by photosynthesis. It has a wide range of applications in candy manufacturing and pharmaceuticals. Shan et al. ${ }^{119}$ found that the fluorescence of boron-doped CDs can be quenched by hydrogen peroxide. As a result, they achieved the rapid and highly sensitive detection of glucose based on the oxidation of glucose catalyzed by glucose oxidase to produce gluconate and hydrogen peroxide. When glucose oxidase and glucose were present, the degree of quenching of the fluorescence of CDs was linearly related to the glucose concentration. The linear range was $8.0-80.0 \mu \mathrm{M}$, and the detection limit was $8.0 \mu \mathrm{M}$.

Phytic acid is the main form of phosphorus in plant tissues (cereals, fruits and vegetables) and is mainly present in the seeds, roots and stems of plants. In the food industry, phytic acid can be used as a food additive; in the wine industry it can be used as a metal-removing agent. Gao et al. ${ }^{120}$ reported a facile, one-step pyrolytic synthesis of photoluminescent CDS using citric acid as the carbon source and lysine as a surface passivation agent. The fluorescence of the CDs was found to be effectively quenched by ferric $\left(\mathrm{Fe}^{3+}\right)$ ions with high selectivity via a photoinduced electron transfer (PET) process. Upon the addition of phytic acid (PA) to a dispersion of the $\mathrm{CDs} / \mathrm{Fe}^{3+}$ complex, the fluorescence of the CDs was significantly recovered as a result of the release of $\mathrm{Fe}^{3+}$ ions from the $\mathrm{CDs} / \mathrm{Fe}^{3+}$ complex, because PA has a higher affinity for $\mathrm{Fe}^{3+}$ ions in comparison with CDs. This analytical method is simple, lowcost and sensitive (linear range 0.68-18.69 $\mu \mathrm{M}$, detection limit $0.36 \mu \mathrm{M}$ ) with high selectivity, stability and recovery ratios for standard and actual samples.

Vitamins are essential to the maintenance of good health. Such substances are neither raw materials that constitute body tissues, nor sources of energy, but a class of regulatory substances that play an important role in the metabolism of substances in the body. Vitamins are a class of trace organic substance that humans and animals must obtain from food in order to maintain normal physiological functions. They play important roles in the body in growth, metabolism, and development. Wang et al. ${ }^{121}$ reported a novel fluorescence resonance energy transfer sensor based on thermally reduced CDs for the determination of vitamin B12 (VB12) in aqueous solutions. When the concentration of VB12 was increased, the fluorescence intensity of the CDs decreased. The CDs were used to detect VB12 at concentrations ranging from $1 \mathrm{mg} \mathrm{mL}^{-1}$ to $12 \mathrm{mg} \mathrm{mL}^{-1}$, and the limit of detection was as low as $0.1 \mathrm{mg} \mathrm{mL}^{-1}$. Furthermore, highly sensitive detection of VB2 and VB9 was also achieved. ${ }^{122,123}$

\subsection{Explosives screening}

In recent years, there has been much international concern over the reliable and accurate detection of explosives. ${ }^{\mathbf{1 2 4 , 1 2 5}}$ In addition, the detection of explosives for preventing terrorist crimes, safeguarding people's lives and property, maintaining national security and protecting the environment and health is of great significance. ${ }^{\mathbf{1 2 6}-\mathbf{1 2 8}}$ Owing to the wide variety of explosives, together with the fact that the vapor pressure of most explosives is very low, the detection of explosives has always been a challenging problem. ${ }^{\mathbf{1 2 9}}$ Nitroaromatic explosives are major environmental pollutants with high toxicity and are difficult to 
degrade. They pose a serious threat to the ecological balance, social stability and national security. ${ }^{\mathbf{1 3 0}}$ Nitroaromatic explosives in the environment are mainly derived from the industrial production of explosives, wastewater generated during the processing of bombs, and military activities. ${ }^{\mathbf{1 3 1}}$ At present, most explosives that are used contain nitroaromatic compounds such as 2,4,6-trinitrotoluene (TNT), dinitrotoluene (DNT) and 2,4,6trinitrophenol (PA, picric acid), etc. Technology for the ultratrace detection of explosives is mainly used to detect vapor from explosives, which adheres to the surface of any object that has been exposed to explosives. Currently, methods for the detection of trace explosives include gas chromatography-mass spectrometry, ${ }^{\mathbf{1 3 2}}$ gas chromatography-electron capture mass spectrometry, ${ }^{133}$ surface-enhanced Raman spectroscopy, ${ }^{134} \mathrm{X}$-ray imaging, ${ }^{135}$ thermal neutron analysis, ${ }^{\mathbf{1 3 6}}$ electrochemical ion mobility spectroscopy, ${ }^{137}$ "explosive dogs", ${ }^{138}$ and so on. The abovementioned detection methods can achieve the sensitive detection of nitroaromatic hydrocarbon explosives. Unfortunately, most of these methods require costly equipment or other cumbersome accessories that are not suitable for the on-site environmental analysis and detection of explosives. Therefore, it is essential to develop new detection techniques to enable the on-site environmental analysis of nitroaromatic explosives. Fluorescence methods are considered to be among the most appropriate techniques because of their high sensitivity, acquisition of multiple parameters, and relatively mature instrument designs. The fluorescence detection of explosives has therefore aroused widespread interest in recent years and has developed rapidly. One of the most notable experts in this field is Professor Swager of the Massachusetts Institute of Technology (MIT), who achieved breakthroughs in the detection of explosives by utilizing conjugated organic polymer films. ${ }^{\mathbf{1 3 9 - 1 4 1}}$ However, the syntheses of such conjugated organic polymer materials are time-consuming and costly, and problems arise such as the photobleaching and chemical degradation of fluorescent organic materials. Therefore, the development of new fluorescent materials with high resistance to photobleaching and degradation ability has become the focus of research on fluorescence detection of nitroaromatic explosives. QDs, which are a new kind of fluorescent nanoprobe, have high quantum yields, long-term stability, and strong resistance to photobleaching. The fluorescence intensity and stability of QDs are 20 times and 100 times higher than those of fluorescent organic materials, respectively. ${ }^{\mathbf{1 4 2}}$ Moreover, QDs also have excellent fluorescence characteristics such as wide excitation spectra, narrow emission spectra, precisely controlled emission wavelengths, etc., which possess obvious advantages in the detection of nitroaromatic explosives, in particular the rapid screening of explosives. ${ }^{\mathbf{1 4 3 , 1 4 4}}$ However, QDS have the disadvantage of the inherent toxicity of heavy metals, and the use of noble metal clusters involves high costs. Recently, CDs have attracted extensive attention owing to their unique properties, such as green synthesis, excellent solubility, easy functionalization, and high biocompatibility, etc. As a green substitute for QDs, CDs have found further promising applications in the trace detection of explosives.
During the World Wars, huge amounts of TNT were released into the soil, lakes, and rivers. As an environmental contaminant, the explosive nitroaromatic compound TNT has aroused social concern. Currently, TNT continues to be a major component of ordnance used by the military and terrorists, which causes environmental damage and threatens public security. ${ }^{145-147}$ Therefore, the development of practicable analytical platforms for monitoring ultra-trace levels of TNT is urgently necessary. Zhang et al. ${ }^{148}$ successfully synthesized $\mathrm{N}$ rich CDs via a microwave-assisted pyrolysis method and employed them in both the fluorescence and the electrochemical determination of TNT. The fluorescence sensing platform was based on the strong interaction between TNT and amino groups, which can quench the PL of CDs via charge transfer. The resulting linear detection range extended from $10 \mathrm{nM}$ to $1.5 \mu \mathrm{M}$, with a short response time of $30 \mathrm{~s}$. A glassy carbon electrode modified with CDs exhibited high ability for the reduction of TNT, with a linear detection range extending from $5 \mathrm{nM}$ to $30 \mu \mathrm{M}$, which was greater than that obtained by the fluorescence method. Fig. 10a compares differential pulse voltammograms (DPVs) corresponding to $5 \mu \mathrm{M}$ TNT recorded at the bare glassy carbon (GC) electrode and the CDs/GC electrode. The DPV responses to different concentrations of TNT are shown in Fig. 10b. At low concentrations, only the first wave could be observed. With an increase in the TNT concentration, the other two waves appeared sequentially, and the peak
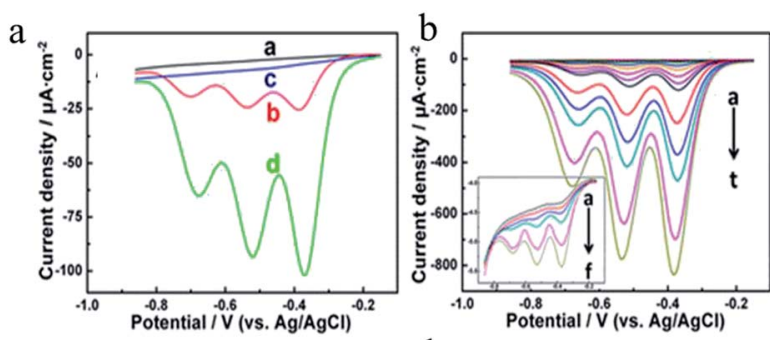

$\mathrm{c}$
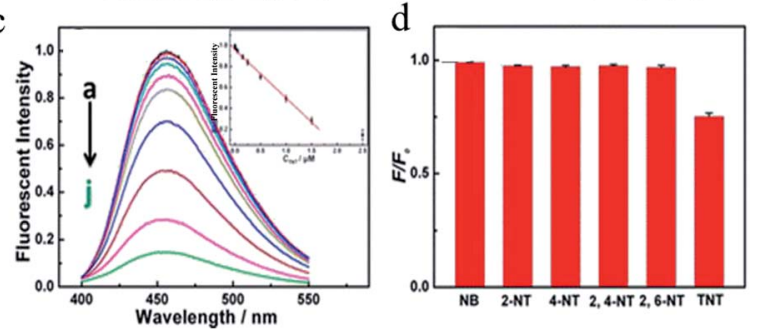

Fig. 10 (a) Differential pulse voltammograms (DPVs) recorded at a bare glassy carbon (GC) electrode ( $a, b)$ and a CDs/GC electrode (c, d) in $0.1 \mathrm{M} \mathrm{N}_{2}$-saturated PBS (containing $0.2 \mathrm{M} \mathrm{KCl}$ ) at a pH of 7.0 with (b, d) and without (a, c) $5 \mu M$ TNT. (b) DPVs recorded corresponding to different concentrations of TNT at a CDs/GC electrode (inset: magnification of the low-concentration region) (a-t: blank, $1 \mathrm{nM}, 5 \mathrm{nM}, 10 \mathrm{nM}$, $20 \mathrm{nM}, 30 \mathrm{nM}, 80 \mathrm{nM}, 130 \mathrm{nM}, 230 \mathrm{nM}, 330 \mathrm{nM}, 830 \mathrm{nM}, 1.33 \mu \mathrm{M}$, $2.33 \mu \mathrm{M}, 3.33 \mu \mathrm{M}, 4.33 \mu \mathrm{M}, 9.33 \mu \mathrm{M}, 14.33 \mu \mathrm{M}, 19.33 \mu \mathrm{M}, 29.33 \mu \mathrm{M}$, and $39.33 \mu \mathrm{M})$. (c) The PL intensity responding to different concentrations of TNT and the corresponding calibration plot (c-a-c-j: blank, $1 \mathrm{nM}$, $10 \mathrm{nM}, 50 \mathrm{nM}, 150 \mathrm{nM}, 250 \mathrm{nM}, 500 \mathrm{nM}, 1 \mu \mathrm{M}, 1.5 \mu \mathrm{M}$, and $2.5 \mu \mathrm{M})$. (d) PL changes corresponding to concentrations of $5 \mu \mathrm{M}$ of different interfering substances, as well as $0.5 \mu \mathrm{M}$ TNT. (Reprinted with permission from ref. 148. Copyright 2015, American Chemical Society.) 
currents of the three waves increased in proportion to the TNT concentration. Fig. 10c shows the dependence on the TNT concentration of the changes in the fluorescence of CDs. It was found that the fluorescence gradually decreased in intensity with the continuous addition of TNT owing to the continuous formation of a TNT-amine complex. As shown in Fig. 10d, the quenching ratio for a concentration of $5 \mu \mathrm{M}$ of various analogues was much lower than that for $0.5 \mu \mathrm{M}$ TNT, which suggested that interference with the real sample analysis was negligible. Moreover, the minimum concentration that produced a distinguishable response in these two methods was as low as the nanomolar level with high specificity, which was not only attributed to the high intrinsic activity and large surface area of CDs but also benefited from the cumulative effect of functionalization with amino groups. In comparison with fluorescence determination, the electrochemical method does not require expensive instruments. It is thus more practical and powerful in the field of chemical analysis.

$\mathrm{Xu}$ et $a l .{ }^{\mathbf{1 4 9}}$ developed a facile strategy for preparing a fluorescence sensor based on CDs capped by molecularly imprinted polymers with mesoporous structures (M-MIPs@CDs) for the highly sensitive and selective determination of TNT. The strategy, which used amino-CDs directly as a "functional monomer" for imprinting, simplified the imprinting process and provided highly accessible recognition sites. The asprepared M-MIPs@CDs sensor, which used periodic mesoporous silica as the imprinting matrix and amino-CDs directly as a "functional monomer", exhibited excellent selectivity and sensitivity toward TNT, with a detection limit of $17 \mathrm{nM}$. The detection process could be repeated 10 times with no obvious decrease in efficiency. The feasibility of the developed method for real sample analysis was successfully demonstrated by the analysis of TNT in soil and water samples, with satisfactory recoveries of $88.6-95.7 \%$.

TNP, also known as picric acid, which is a nitroaromatic explosive with higher explosive power and thermal expansion than other nitroaromatic compounds such as TNT, has been widely used in the preparation of matches and fireworks ${ }^{150,151}$ and has become a great threat to the environment, homeland security and public safety. With regard to the significance of TNP, it is highly desirable to develop simple analytical methods, in particular an effective and selective sensor, for detecting trace amounts of TNP. Chen et al. ${ }^{152}$ first prepared CDs doped with rare earths with multifunctional properties by simply keeping a mixture of terbium(III) nitrate pentahydrate and citric acid at $190{ }^{\circ} \mathrm{C}$ for $30 \mathrm{~min}$. The as-prepared terbiumdoped CDs (Tb-CDs), which were synthesized via a rapid and simple direct carbonization route, had a size of about $3 \mathrm{~nm}$. They exhibited blue fluorescence emissions that depended on the excitation wavelength, were stable, and were employed for the selective colorimetric detection of TNP in the range of $500 \mathrm{nM}$ to $100 \mu \mathrm{M}$ with a limit of detection of $200 \mathrm{nM}$. Liu et $a{ }^{153}$ developed a selective and sensitive method for the detection of TNP with a limit of detection of $28 \mathrm{nM}$ using amorphous photoluminescent CDs, which were prepared via a simple hydrothermal route using spermine and $m$-phenylenediamine as precursors. The as-prepared CDs were found to exhibit blue-green photoluminescence that was independent of the excitation wavelength and excellent chemical and optical stability.

\section{Conclusions}

This review has highlighted recent progress in the field of CDs in terms of their rational synthesis, tunable optical properties and analytical applications. Currently, although various facile synthetic methods have been used for the preparation of CDs, well-defined and atom-precise structures have not yet been reported, which is important for studies of the relationships between structure and properties and the investigation of new methods and applications. In addition, the mechanisms underlying their tunable PL properties are still a highly controversial issue. This is mainly due to inconsistent experimental observations caused by the great heterogeneity of samples of CDs, even when produced by the same synthetic method, as well as the diverse, obscure and poorly defined properties of CDs obtained by different preparation processes. In comparison with traditional semiconducting quantum dots, fluorescent CDs have comparable fluorescence characteristics and also have low toxicity, excellent biocompatibility and environment-friendliness because they essentially comprise carbon. Although there are many methods for the synthesis of CDs, which tend to be simple and give high yields, there is still a large difference in fluorescence quantum yield between CDs and semiconductor quantum dots, and their low quantum yields greatly limit their applications. Therefore, it is still a great challenge to achieve high fluorescence quantum yields with large-scale preparation methods and precise control of the structure and size of CDs. Moreover, it is necessary to improve the sensitivity and resistance to interference of CDs and further optimize their synthesis and modification methods. Furthermore, to improve both the synthesis process of CDs and the understanding of their PL properties, it is necessary to advance research into their PL mechanism. Finally, it is anticipated by researchers that increasing effort will be devoted to research into CDs, and much more progress with CDs will be made in other fields (e.g., electrocatalysis, photocatalysis, cancer therapy, etc.). It seems clear that the future of CDs remains promising.

\section{Conflicts of interest}

There are no conflicts to declare.

\section{Acknowledgements}

This work is supported by the National Basic Research Program of China (2015CB932002), China-Singapore Joint Project (2015DFG92510), Science and Technology Service Network Initiative of Chinese Academy of China (KFJ-SW-STS-172), and National Natural Science Foundation of China (No. 21371174, 21671052, 21375131, and 21475135). 


\section{References}

1 M. Bruchez Jr, M. Moronne, P. Gin, S. Weiss and A. P. Alivisatos, Science, 1998, 281, 2013-2016.

2 X. Michalet, F. F. Pinaud, L. A. Bentolila, J. M. Tsay, S. Doose, J. J. Li, G. Sundaresan, A. M. Wu, S. S. Gambhir and S. Weiss, Science, 2005, 307, 538-544.

3 J. Peng, W. Gao, B. K. Gupta, Z. Liu, R. Romero-Aburto, L. Ge, L. Song, L. B. Alemany, X. Zhan, G. Gao, S. A. Vithayathil, B. A. Kaipparettu, A. A. Marti, T. Hayashi, J. J. Zhu and P. M. Ajayan, Nano Lett., 2012, 12, 844-849.

4 Y. Li, Y. Hu, Y. Zhao, G. Shi, L. Deng, Y. Hou and L. Qu, Adv. Mater., 2011, 23, 776-780.

5 L. Cao, S. Sahu, P. Anikumar, C. E. Bunker, J. A. Xu, K. A. S. Fernando, P. Wang, E. A. Guliants, K. N. Tackett and Y. P. Sun, J. Am. Chem. Soc., 2011, 133, 4754-4757.

6 L. Cao, X. Wang, M. J. Meziani, F. Lu, H. Lou, P. G. Wang, Y. Lin, B. A. Harruff, L. M. Veca, D. Murray, S. Y. Xie and Y. P. Sun, J. Am. Chem. Soc., 2007, 129, 11318-11319.

7 P. Anilkumar, X. Wang, L. Cao, S. Sahu, J. H. Liu, P. Wang, L. L. Tian, K. W. Sun, M. A. Bloodgood and Y. P. Sun, Nanoscale, 2011, 3, 2023-2027.

8 X. Y. Xu, R. Ray, Y. L. Gu, H. J. Ploehn, L. Gearheart, K. Raker and W. A. Scrivens, J. Am. Chem. Soc., 2004, 126, 12736-12737.

9 Y. P. Sun, B. Zhou, Y. Lin, W. Wang, K. A. S. Fernando, P. Pathak, M. J. Meziani, B. A. Harruff, X. Wang, H. F. Wang, P. G. Luo, H. Yang, M. E. Kose, B. L. Chen, L. M. Veca and S. Y. Xie, J. Am. Chem. Soc., 2006, 128, 7756-7757.

$10 \mathrm{~J} . \mathrm{Xu}, \mathrm{S} . \mathrm{Sahu}, \mathrm{L}$. Cao, P. Anilkumar, K. N. Tackett, H. J. Qian, C. E. Bunker, E. A. Guliants, A. Parenzan and Y. P. Sun, ChemPhysChem, 2011, 12, 3604-3608.

11 P. Anikumar, X. Wang, L. Cao, S. Sahu, J. H. Liu, P. Wang, K. Korch, K. N. Tackett, A. Parenzan and Y. P. Sun, Nanoscale, 2011, 3, 2023-2027.

12 S. N. Baker and G. A. Baker, Angew. Chem., Int. Ed., 2010, 49, 6726-6744.

13 S. N. Qu, X. Y. Wang, Q. P. Lu, X. Y. Liu and L. J. Wang, Angew. Chem., Int. Ed., 2012, 51, 12215-12218.

14 S. J. Zhu, Q. N. Meng, L. Wang, J. H. Zhang, Y. B. Song, H. Jin, K. Zhang, H. C. Sun, H. Y. Wang and B. Yang, Angew. Chem., Int. Ed., 2013, 52, 3953-3957.

15 K. Lingam, R. Podila, H. J. Qian, S. Serkiz and A. M. Rao, Adv. Funct. Mater., 2013, 23, 5062-5065.

16 X. Y. Zhang, Y. Zhang, Y. Wang, S. Kalytchuk, S. V. Kershaw, Y. H. Wang, P. Wang, Y. Zhao and H. Z. Zhang, ACS Nano, 2013, 7, 11234-11241.

17 S. L. Hu, K. Y. Niu, J. Sun, J. Yang, N. Q. Zhao and X. W. Du, J. Mater. Chem., 2009, 19, 484-488.

18 S. T. Yang, X. Wang, H. F. Wang, F. S. Lu, P. G. J. Luo, L. Cao, M. J. Meziani, J. H. Liu, Y. F. Liu, M. Chen, Y. P. Huang and Y. P. Sun, J. Phys. Chem. C, 2009, 113, 18110-18114.

19 H. T. Li, X. D. He, Z. H. Kang, H. Huang, Y. Liu, J. H. Liu, S. Y. Lian, C. H. A. Tsang, X. B. Yang and S. T. Lee, Angew. Chem., Int. Ed., 2010, 122, 4532-4536.
20 H. Ming, Z. Ma, Y. Liu, K. Pan, H. Yu, F. Wang and Z. H. Kang, Dalton Trans., 2012, 41, 9526-9531.

21 J. G. Zhou, C. Booker, R. Li, X. T. Zhou, T. K. Sham, X. L. Sun and Z. F. Ding, J. Am. Chem. Soc., 2007, 129, 744-745.

22 Q. L. Zhao, Z. L. Zhang, B. H. Huang, J. Peng, M. Zhang and D. W. Pang, Chem. Commun., 2008, 5116-5118.

23 L. Y. Zheng, Y. W. Chi, Y. Q. Dong, J. P. Lin and B. B. Wang, J. Am. Chem. Soc., 2009, 131, 4564-4565.

24 J. Lu, J. X. Yang, J. Z. Wang, A. Lim, S. Wang and K. P. Loh, ACS Nano, 2009, 3, 2367-2375.

25 S. Yao, Y. F. Hu and G. K. Li, Carbon, 2014, 66, 77-83.

26 M. Bottini, C. Balasubramanian, M. I. Dawson, A. Bergamaschi, S. Bellucci and T. Mustelin, J. Phys. Chem. B, 2006, 110, 831-836.

27 J. C. Vinci and L. A. Colon, Anal. Chem., 2011, 84, 11781183.

28 Y. Liu, C. Y. Liu and Z. Y. Zhang, J. Colloid Interface Sci., 2011, 356, 416-421.

29 Y. F. Sha, J. Y. Lou, S. Z. Bai, D. Wu, B. Z. Li and Y. Ling, Mater. Res. Bull., 2013, 48, 1728-1731.

30 S. Liu, J. Q. Tian, L. Wang, Y. W. Zhang, X. Y. Qin, Y. L. Luo, A. M. Asiri, A. O. Al-Youbi and X. P. Sun, Adv. Mater., 2012, 24, 2037-2041.

31 Y. Liu, C. Y. Liu and Z. Y. Zhang, Appl. Surf. Sci., 2012, 263, 481-485.

32 A. B. Bourlinos, A. Stassinopoulos, D. Anglos, R. Zboril, M. Karakassides and E. P. Giannelis, Small, 2008, 4, 455458.

33 H. Peng and J. Travas-Sejdic, Chem. Mater., 2009, 21, 55635565.

34 H. T. Li, X. D. He, Y. Liu, H. Huang, S. Y. Lian, S. T. Lee and Z. H. Kang, Carbon, 2011, 49, 605-609.

35 R. L. Liu, D. Q. Wu, S. H. Liu, K. Koynov, W. Knoll and Q. Li, Angew. Chem., Int. Ed., 2009, 121, 4668-4671.

36 H. P. Liu, T. Ye and C. D. Mao, Angew. Chem., Int. Ed., 2007, 46, 6473-6475.

37 S. C. Ray, A. Saha, N. R. Jana and R. Sarkar, J. Phys. Chem. C, 2009, 113, 18546-18551.

38 L. Tian, D. Ghosh, W. Chen, S. Pradhan, X. J. Chang and S. W. Chen, Chem. Mater., 2009, 21, 2803-2809.

39 A. B. Bourlinos, A. Stassinopoulos, D. Anglos, R. Zboril, V. Georgakilas and E. P. Giannelis, Chem. Mater., 2008, 20, 4539-4541.

40 Y. X. Yang, D. Q. Wu, S. Han, P. F. Huc and R. L. Liu, Chem. Commun., 2013, 49, 4920-4922.

41 J. Zong, Y. H. Zhu, X. L. Yang, J. H. Shen and C. Z. Li, Chem. Commun., 2011, 47, 764-766.

42 F. Wang, S. P. Pang, L. Wang, Q. Li, M. Kreiter and C. Y. Liu, Chem. Mater., 2010, 22, 4528-4530.

43 Z. Xie, F. Wang and C. Y. Liu, Adv. Mater., 2012, 24, 17161721.

44 F. Wang, Z. Xie, H. Zhang, C. Y. Liu and Y. G. Zhang, Adv. Funct. Mater., 2011, 21, 1027-1031.

45 D. Y. Pan, J. C. Zhang, Z. Li, C. Wu, X. M. Yan and M. H. Wu, Chem. Commun., 2010, 46, 3681-3683.

46 R. L. Liu, D. Q. Wu, X. L. Feng and K. MÜllen, J. Am. Chem. Soc., 2011, 133, 15221-15223. 
47 D. Sun, R. Ban, P. H. Zhang, G. H. Wu, J. R. Zhang and J. J. Zhu, Carbon, 2013, 64, 424-434.

48 M. B. Wu, Y. Wang, W. T. Wu, C. Hu, X. N. Wang, J. T. Zheng, Z. T. Li, B. Jiang and J. S. Qiu, Carbon, 2014, 78, 480-489.

49 H. Zhu, X. L. Wang, Y. L. Li, Z. J. Wang, F. Yang and X. R. Yang, Chem. Commun., 2009, 5118-5120.

50 C. J. Liu, P. Zhang, F. Tian, W. C. Li, F. Li and W. G. Liu, J. Mater. Chem., 2011, 21, 13163-13167.

51 C. J. Liu, P. Zhang, X. Y. Zhai, F. Tian, W. C. Li, J. Yang, Y. H. Liu, H. G. Wang, W. Wang and W. G. Liu, Biomaterials, 2012, 33, 3604-3613.

52 B. Zhang, C. Y. Liu and Y. Liu, Eur. J. Inorg. Chem., 2010, 2010, 4411-4414.

53 J. Li, B. Zhang, F. Wang and C. Y. Liu, New J. Chem., 2011, 35, 554-557.

54 S. Sahu, B. Behera, T. K. Maitib and S. Mohapatra, Chem. Commun., 2012, 48, 8835-8837.

55 Y. H. Yang, J. H. Cui, M. T. Zheng, C. F. Hu, S. Z. Tan, Y. Xiao, Q. Yang and Y. L. Liu, Chem. Commun., 2012, 48, 380-382.

56 J. Li, Y. Liu, Q. Shu, J. Liang, F. Zhang, X. Chen, X. Deng, M. T. Swihart and K. Ten, Langmuir, 2017, 33, 1043-1050.

57 W. Kwon and S. Rhee, Chem. Commun., 2012, 48, 52565258.

58 Y. H. Deng, D. X. Zhao, X. Chen, F. Wang, H. Song and D. Z. Shen, Chem. Commun., 2013, 49, 5751-5753.

59 C. Sun, Y. Zhang, S. Kalytchuk, Y. Wang, X. Y. Zhang, W. Z. Gao, J. Zhao, K. Cepe, R. Zboril, W. W. Yu and A. L. Rogach, J. Mater. Chem. C, 2015, 3, 6613-6615.

60 B. Liao, P. Long, B. Q. He, S. J. Yi, B. L. Ou, S. H. Shen and J. Chen, J. Mater. Chem. C, 2013, 1, 3716-3721.

61 Z. Lin, W. Xue, H. Chen and J. M. Lin, Chem. Commun., 2012, 48, 1051-1053.

62 W. J. Miao, Chem. Rev., 2008, 108, 2506-2553.

63 W. Xue, Z. Lin, H. Chen, C. Lu and J. M. Lin, J. Phys. Chem. $C, 2011,115,21707-21714$.

64 Y. Q. Dong, N. N. Zhou, X. M. Lin, J. P. Lin, Y. W. Chi and G. N. Chen, Chem. Mater., 2010, 22, 5895-5899.

65 C. N. Zhong, P. P. Yang, X. B. Li, C. X. Li, D. Wang, S. L. Gaia and J. Lin, RSC Adv., 2012, 2, 3194-3197.

66 C. X. Li, Z. Y. Hou, Y. L. Dai, D. M. Yang, Z. Y. Cheng, P. A. Ma and J. Lin, Biomater. Sci., 2013, 1, 213-223.

67 Y. Wang and A. Hu, J. Mater. Chem. C, 2014, 2, 6921-6939.

68 B. D. Yin, J. H. Deng, X. Peng, Q. Long, J. N. Zhao, Q. J. Lu, Q. Chen, H. T. Li, H. Tang, Y. Y. Zhang and S. Z. Yao, Analyst, 2013, 138, 6551-6557.

69 B. De and N. Karak, RSC Adv., 2013, 3, 8286-8290.

70 Q. T. Huang, S. R. Hu, H. Q. Zhang, J. H. Chen, Y. S. He, F. M. Li, W. Weng, J. C. Ni, X. X. Bao and Y. Lin, Analyst, 2013, 138, 5417-5423.

71 Y. Q. Dong, J. W. Shao, C. Q. Chen, H. Li, R. X. Wang, Y. W. Chi, X. M. Lin and G. N. Chen, Carbon, 2012, 50, 4738-4743.

72 X. H. Wang, K. G. Qu, B. L. Xu, J. S. Ren and X. G. Qu, Nano Res., 2011, 4, 908-920.

73 P. Shen and Y. Xia, Anal. Chem., 2014, 86, 5323-5329.
74 H. X. Zhao, L. Q. Liu, Z. D. Liu, Y. Wang, X. J. Zhao and C. Z. Huang, Chem. Commun., 2011, 47, 2604-2606.

75 W. Shi, X. H. Li and H. M. Ma, Angew. Chem., Int. Ed., 2012, 124, 6538-6541.

76 A. W. Zhu, Q. Qu, X. L. Shao, B. Kong and Y. Tian, Angew. Chem., Int. Ed., 2012, 124, 7297-7301.

77 W. L. Wei, C. Xu, J. S. Ren, B. L. Xu and X. G. Qu, Chem. Commun., 2012, 48, 1284-1286.

78 M. Zheng, Z. G. Xie, D. Qu, D. Li, P. Du, X. B. Jing and Z. C. Sun, ACS Appl. Mater. Interfaces, 2013, 5, 1324213247.

79 C. M. Yu, X. Z. Li, F. Zeng, F. Y. Zheng and S. Z. Wu, Chem. Commun., 2013, 49, 403-405.

80 F. K. Du, Y. H. Min, F. Zeng, C. M. Yu and S. Z. Wu, Small, 2014, 10, 964-972.

81 Q. Li, T. Ohulchanskyy, R. Liu, K. Koynov, D. Wu, A. Best, R. Kumar, A. Bonoiu and P. Prasad, J. Phys. Chem. C, 2010, 114, 12062-12068.

82 S. T. Yang, L. Cao, P. J. G. Luo, F. S. Lu, X. Wang, H. F. Wang, M. J. Meziani, Y. F. Liu, G. Qi and Y. P. Sun, J. Am. Chem. Soc., 2009, 131, 11308-11309.

83 L. Zhou, Y. H. Lin, Z. Z. Huang, J. S. Ren and X. G. Qu, Chem. Commun., 2012, 48, 1147-1149.

84 Y. M. Guo, Z. Wang, H. W. Shao and X. Y. Jiang, Carbon, 2013, 52, 583-589.

85 W. B. Lu, X. Y. Qin, S. Liu, G. H. Chang, Y. W. Zhang, Y. L. Luo, A. M. Asiri, A. O. Al-Youbi and X. P. Sun, Anal. Chem., 2012, 84, 5351-5357.

86 C. Yuan, B. H. Liu, F. Liu, M. Y. Han and Z. P. Zhang, Anal. Chem., 2014, 86, 1123-1130.

87 R. L. Zhang and W. Chen, Biosens. Bioelectron., 2014, 55, 8390.

88 Y. Wang, S. H. Kim and L. Feng, Anal. Chim. Acta, 2015, 890, 134-142.

89 X. J. Wan, S. F. Li, L. L. Zhuang and J. N. Tang, J. Nanopart. Res., 2016, 18, 1-9.

90 X. J. Liu, N. Zhang, T. Bing and D. H. Shangguan, Anal. Chem., 2014, 86, 2289-2296.

91 Y. Q. Dong, R. X. Wang, G. L. Li, C. Q. Chen, Y. W. Chi and G. N. Chen, Anal. Chem., 2012, 84, 6220-6224.

92 X. M. Lin, G. M. Gao, L. Y. Zheng, Y. W. Chi and G. N. Chen, Anal. Chem., 2013, 86, 1223-1228.

93 A. D. Zhao, C. Q. Zhao, M. Li, J. S. Ren and X. G. Qu, Anal. Chim. Acta, 2014, 809, 128-133.

94 A. Salinas-Castillo, M. Ariza-Avidad, C. Pritz, M. CamprubíRobles, B. Fernández, M. J. Ruedas-Rama, A. MegiaFernández, A. Lapresta-Fernández, F. Santoyo-Gonzalez, A. Schrott-Fischer and L. F. Capitan-Vallvey, Chem. Commun., 2013, 49, 1103-1105.

95 K. G. Qu, J. S. Wang, J. S. Ren and X. G. Qu, Chem.-Eur. J., 2013, 19, 7243-7249.

96 F. X. Wang, Q. L. Hao, Y. H. Zhang, Y. J. Xu and W. Lei, Microchim. Acta, 2016, 183, 273-279.

97 S. N. Qu, H. Chen, X. M. Zheng, J. S. Cao and X. Y. Liu, Nanoscale, 2013, 5, 5514-5518.

98 H. Wu, J. Jiang, X. Gu and C. Tong, Microchim. Acta, 2017, 1-8. 
99 H. L. Li, J. F. Zhai and X. P. Sun, Langmuir, 2011, 27, 43054308.

100 Z. S. Qian, J. J. Ma, X. Y. Shan, H. Feng, L. X. Shao and J. R. Chen, Chem.-Eur. J., 2014, 20, 2254-2263.

101 S. S. Wee, Y. H. Ng and S. M. Ng, Talanta, 2013, 116, 71-76. 102 S. N. A. M. Yazid, S. F. Chin, S. C. Pang and S. M. Ng, Microchim. Acta, 2013, 180, 137-143.

103 M. Zheng, Z. Xie, D. Qu, D. Li, P. Du, X. Jing and Z. Sun, ACS Appl. Mater. Interfaces, 2013, 5, 13242-13247.

104 Y. H. Zhang, H. S. Zhang, X. F. Guo and H. Wang, Microchem. J., 2008, 89, 142-147.

105 Z. Q. Liu, S. P. Liu, P. F. Yin and Y. Q. He, Anal. Chim. Acta, 2012, 745, 78-84.

106 Y. H. Chan, J. X. Chen, Q. S. Liu, S. E. Wark, D. H. Son and J. D. Batteas, Anal. Chem., 2010, 82, 3671-3678.

107 C. L. Xie, L. Xiao, S. Z. Peng and X. W. Shi, New J. Chem., 2014, 38, 6095-6102.

108 X. Y. Sun, P. C. Liu, L. L. Wu and B. Liu, Analyst, 2015, 140, 6742-6747.

109 Z. Lin, W. Xue, H. Chen and J. M. Lin, Anal. Chem., 2011, 83, 8245-8251.

110 J. M. Liu, L. Lin, X. X. Wang, J. Li, M. Cui, S. Jiang, W. Cai, L. Zhang and Z. Zheng, Analyst, 2013, 138, 278-283.

111 X. F. Hou, F. Zeng, F. K. Du and S. Z. Wu, Nanotechnology, 2013, 24, 335502.

112 S. Barman and M. Sadhukhan, J. Mater. Chem., 2012, 22, 21832-21837.

113 S. R. Zhang, Q. Wang, G. G. Tian and H. G. Ge, Mater. Lett., 2014, 115, 233-236.

114 Y. Q. Dong, R. X. Wang, W. R. Tian, Y. W. Chi and G. N. Chen, $R S C A d v$., 2014, 4, 3701-3705.

115 X. Gao, C. Ding, A. Zhu and Y. Tian, Anal. Chem., 2014, 86, 7071-7078.

116 T. Tanaka, Food Chem. Toxicol., 2006, 44, 179-187.

117 K. A. Amin, H. A. Hameid and A. H. Abd Elsttar, Food Chem. Toxicol., 2010, 48, 2994-2999.

118 H. P. Xu, X. Yang, G. Li, C. Zhao and X. J. Liao, J. Agric. Food Chem., 2015, 63, 6707-6714.

119 X. Y. Shan, L. J. Chai, J. J. Ma, Z. S. Qian, J. R. Chen and H. Feng, Analyst, 2014, 139, 2322-2325.

120 Z. Gao, L. B. Wang, R. X. Su, R. L. Huang, W. Qi and Z. M. He, Biosens. Bioelectron., 2015, 70, 232-238.

121 J. L. Wang, J. H. Wei, S. H. Su and J. J. Qiu, New J. Chem., 2015, 39, 501-507.

122 Z. B. Chen, J. Wang, H. Miao, L. Wang, S. Wu and X. M. Yang, Sci. China: Chem., 2016, 59, 487-492.

123 A. Kundu, S. Nandi, P. Das and A. K. Nandi, J. Colloid Interface Sci., 2016, 468, 276-283.

124 S. S. R. Dasary, D. Senapati, A. K. Singh, Y. Anjaneyulu, H. Yu and P. C. Ray, ACS Appl. Mater. Interfaces, 2010, 2, 3455-3460.

125 Y. Yang, G. A. Turnbull and D. W. Samuel, Adv. Funct. Mater., 2010, 20, 2093-2097.
126 Y. Wang, A. La, Y. Ding, Y. X. Liu and Y. Lei, Adv. Funct. Mater., 2012, 22, 3547-3555.

127 S. Kumar, N. Venkatramaiah and S. Patil, J. Phys. Chem. C, 2013, 117, 7236-7245.

128 H. F. Leng, Q. Y. Niu and W. H. Wu, Polym. Int., 2013, 62, 1187-1191.

129 W. E. Tenhaeff, L. D. McIntosh and K. K. Gleason, Adv. Funct. Mater., 2010, 20, 1144-1151.

130 K. S. Ju and R. E. Parales, Microbiol. Mol. Biol. Rev., 2010, 74, 250-272.

131 J. D. Rodgers and N. J. Bunce, Water Res., 2001, 35, 21012111.

132 K. Hakansson, R. V. Coorey, R. A. Zubarev, V. L. Talrose and P. Hakansson, J. Mass Spectrom., 2000, 35, 337-346.

133 M. E. Walsh, Talanta, 2001, 54, 427-438.

134 J. M. Sylvia, J. A. Janni, J. D. Klein and K. M. Spencer, Anal. Chem., 2000, 72, 5834-5840.

135 S. F. Hallowell, Talanta, 2001, 54, 447-458.

136 G. Vourvopoulos and P. C. Womble, Talanta, 2001, 54, 459468.

137 G. A. Eiceman and J. A. Stone, Anal. Chem., 2004, 390-A.

138 K. G. Furton and L. J. Myers, Talanta, 2001, 54, 487-500.

139 J. S. Yang and T. M. Swager, J. Am. Chem. Soc., 1998, 120, 11864-11873.

140 A. Rose, Z. G. Zhu, C. F. Madigan, T. M. Swager and V. Bulović, Nature, 2005, 434, 876-879.

141 S. Zahn and T. M. Swager, Angew. Chem., Int. Ed., 2002, 41, 4225-4230.

142 W. C. W. Chan and S. M. Nie, Science, 1998, 281, 2016-2018.

143 V. P. Schnee, M. D. Woodka and D. Pinkham, SPIE Defense, Security, and Sensing, International Society for Optics and Photonics, 2012, pp. 83571J-83571J-7.

144 S. Nietoa, A. Santana, S. P. Hernández, R. Lareaub, R. T. Chamberlain and M. E. Castro, Defense and Security, International Society for Optics and Photonics, 2004, pp. 256-260.

145 T. S. Tsai, Hazard. Waste Hazard. Mater., 1991, 8, 231-244. 146 M. Emmrich, Environ. Sci. Technol., 1999, 33, 3802-3805.

147 A. Mills, A. Seth and G. Peters, Phys. Chem. Chem. Phys., 2003, 5, 3921-3927.

148 L. L. Zhang, Y. J. Han, J. B. Zhu, Y. L. Zhai and S. J. Dong, Anal. Chem., 2015, 87, 2033-2036.

149 S. F. Xu and H. Z. Lu, Biosens. Bioelectron., 2016, 85, 950956.

150 S. J. Toal and W. C. Trogler, Biosens. Bioelectron., 2016, 85, 950-956.

151 S. R. Zhang, D. Y. Du, J. S. Qin, S. J. Bao, S. L. Li, W. W. He, Y. Q. Lan, P. Shen and Z. M. Su, Chem.-Eur. J., 2014, 20, 3589-3594.

152 B. B. Chen, Z. X. Liu, H. Y. Zoub and C. Z. Huang, Analyst, 2016, 141, 2676-2681.

153 M. L. Liu, B. B. Chen, Z. X. Liub and C. Z. Huang, Talanta, 2016, 161, 875-880. 